\title{
Flood patterns in a catchment with mixed bedrock geology: causes for flashy runoff contributions during storm events
}

\author{
Audrey Douinot ${ }^{1}$, Jean François Iffly ${ }^{1}$, Cyrille Tailliez ${ }^{1}$, Claude Meisch ${ }^{2}$, Laurent Pfister $^{1}$ \\ ${ }^{1}$ Environmental Research and Innovation Department (ERIN), Luxembourg Institute of Science and Technology (LIST), \\ 5 Belvaux, Luxembourg \\ ${ }^{2}$ Administration de la Gestion de l'Eau - Division de l'Hydrologie, 1, avenue du Rock'n'roll, 4361 Esch-sur-Alzette, \\ Luxembourg
}

Correspondence to: A. Douinot (audreydouinot@gmail.com)

Abstract.

10 With flash flood events having been repeatedly observed in Central and Western Europe in recent years, there is a growing interest in how catchment physiographic properties and hydrological conditions are eventually controlling rapid and concentrated hydrological responses. Here, we focus on a set of two nested catchments in Luxembourg (Europe) that have been exposed in 2016 and 2018 to flash flood events. While being of similar size $\left(\sim 30 \mathrm{~km}^{2}\right)$ and having analogous hydrological distance distributions, their geological bedrock and landscape features are notably different. The upper

15 catchment (KOE) is dominated by marly bedrock (Km3) and moderately steep Luxembourg sandstone outcrops (Li2). The lower catchment has its drainage network deeply cut into the Luxembourg sandstone, with half of it being covered by marly plateaus (Li3) featuring heavy clay soil. Based on data generated from a dedicated hydro-meteorological monitoring network, we calculated for 23 rainfall-runoff events observed between August 2019 and July 2020 the corresponding net rainfall transfer time distributions (TTDs) from the hillslopes to the catchment outlet. We then compared the TTD properties

20 and related them to the catchment's hydrological state and rainfall properties.

We observed a seasonality in TTDs for both catchments, albeit controlled by different factors. In the KOE catchment, we found the water transfer time to be essentially driven by onset and cessation of hydrological connectivity on the flat marly terrain - the latter operating like a variable contributing area in terms of deep soil storage dynamics (except for one summer event). The HM section exhibits contrasted TTDs throughout the year, suggesting threshold dependent hydrological 25 processes. More specifically, particularly quick runoff transfers seem to dominate under dry conditions. Correlation analyses compared to the literature on runoff generation on the one hand and our descriptive knowledge of the catchments on the other hand suggest multiple causes for the triggering of these rapid flows. The fractured marly plateaus, but also the hydrophobic forest litter forming during dry conditions, stand as our main hypotheses in this respect. Moreover, the absence of a riparian zone, preventing any dampening of (observed) abrupt and massive flows during extreme precipitation events,

30 seems as well to be a key feature of the rapid runoff transfer.

For improving our understanding and forecasting capabilities in Luxembourg (and more broadly in the nearby regions of Germany, Belgium and France with similar physiographic and climate conditions), we recommend further studies focusing 
on catchments with fractured bedrock and limited riparian zones. Special attention may equally be given to the hypothesized responses of forest litter and marly soils to heavy precipitation events occurring after extended dry spells.

\section{Introduction}

\subsection{Background}

One key aspect of flood risk management consists in determining vulnerable areas exposed to hydrological hazard. When affecting built areas, flash floods can be particularly destructive due to: i) their short time of occurrence that leaves very limited or no time to the population for protecting their lives and properties (e.g., evacuation of people and goods, flood

40 fencing); ii) a very rapid concentration of water volumes, leading to high - or even extreme - flood peaks.

Such sudden and devastating flood events are commonly referred to as "flash floods". The non-exhaustive emergency events database (EM-DAT, www.emdat.be consulted on 27.07.2020) has reported no less than 550 fatalities, 616.760 affected inhabitants and 17.6 billion US\$ of damage related to flash floods in Europe over the past 20 years. They have been extensively studied precisely because of their high destructive potential for exposed populations and infrastructures. More than 170 publications with the keyword "flash flood" have been listed in Scopus every year since 2015.

So far, studies on flash floods in Europe mainly focused on the Mediterranean area (MA) (Pereira et al, 2017; Llasat et al, 2016; Marchi et al, 2010; Ducrocq et al, 2014; Diakakis et al, 2017; Saber et al, 2018; Gaume et al, 2016). These studies show that the rainfall properties - more specifically the maximum amount of precipitation accumulated in a few hours - are of paramount importance for flash flood generation. However, many of these studies also pointed out the discrepancies of

50 flash flood responses between catchments with contrasting geological substrate - the latter appearing to control the general flood shape, even in those very specific cases of quick storm flow generation processes (Payrastre et al, 2012; Vannier et al, 2013; Douinot et al, 2018). Likewise, catchment water storage prior to these extreme events is determining the magnitude of the hydrological response (Massari et al, 2020; Tramblay et al, 2010; Berghuijs et al, 2019).

Headwaters are most likely to be impacted by flash flood type hydrological events. Orographic rainfall forcing can lead to

55 intense and prevailing precipitation on catchments located at higher altitude. Steep hillslopes are intuitively perceived as contributing to a rapid concentration of the surface and subsurface flow, eventually leading to a quick transfer of runoff. Moreover, mountainous catchments may exhibit a more fractured bedrock, as they are subject to higher structural constraints (Miller et Dunne, 1996; Molnar, 2004; Slim et al, 2015). The numerous faults and cracks support quick water transfer through the weathered bedrock and explain fast hydrological responses, even though the soil can be highly permeable (Braud 60 et al. 2016 (en); Braud 2015 (fr)).

In recent years, flash flood events have been reported for catchments located in Central Europe (Ruiz-Villanueva et al, 2012; Van Campenhout et al, 2015; Bronstaert et al, 2018; Bryndal et al, 2015). For example, two flash floods have occurred in 2016 and 2018 in Luxembourg (Pfister et al, 2018 \& 2020). While the runoff coefficients determined for these events 
remained rather moderate (12\% - 25\%, Pfister et al, 2020), their almost instantaneous and non-attenuated hydrological response was very unusual for this physiographic and climate setting.

While most flash flood related literature published to date refers to the Mediterranean area (MA), the processes underlying flash floods in Central Europe remain poorly understood. This mainly relates to the fact that in these catchments (i) the climate forcing is not primarily controlled by topography (as opposed to MA), (ii) catchment storage filling states are very different between early summer (storage levels being still high when flash floods occur in Central European catchments) and autumn (storage levels being low when flash floods occurr in MA catchments), and (iii) the underlying bedrock geology is very different between Central European and MA catchments.

Within Central Europe, Luxembourg stands as an ideal hydrological test bed, located mostly inside the Moselle River basin. The country embraces a wide range of nested (headwater \& mesoscale) catchments with various bedrock types and contrasted physiographic settings - covering a relatively small area $\left(\sim 2600 \mathrm{~km}^{2}\right)$ exposed to a rather homogenous pluviooceanic climate. The rainfall-runoff transformation has been extensively characterized and shows strong geological controls (Fenicia et al, 2014; Wrede et al, 2015; Pfister et al, 2017).

For a set of 16 nested catchments in Luxembourg, Pfister et al (2017) reported very contrasted hydrological functions of water collection, storage and release. By leveraging 9 years worth of hydro-meteorological and stream isotopic data, they were able to document that a catchment's resilience to variable meteorological conditions is largely controlled by bedrock geology. Less permeable bedrock will lead to smaller catchment storage capacity, larger seasonal variability in runoff coefficients, and smaller catchment mean transit times.

Wrede et al (2015) and Fenicia et al (2014) confirmed the threshold (or seasonally contrasted) behaviour of impermeable catchments. Using either a modelling framework over long-term time series or geochemical tracing of two events, they concluded that non-linear models are more appropriate for simulating rainfall-runoff responses, and that the pre-event water

85 proportions differ between seasons. Note that the catchment with a higher bedrock permeability (composed of sandstone) is characterized by a more stable reservoir that is reasonably well simulated by a linear model.

\subsection{Status Quo}

To date, all investigations focusing on rainfall-runoff transformation processes in the Luxembourg context have been limited to events of moderate intensity. While these studies have substantially improved our understanding of physiographic controls

90 on runoff generation, we still have poor knowledge of the processes leading to flash flood events in our area of interest. In flash flood prevention related research, the interest is not only set on runoff volumes, but also on the high reactivity, magnitude and intensity of the related hydrological response. Here, we ask - in the context of a Central European study area - what is influencing the specific flash flood event patterns. We leverage prior work in our nested catchment set-up and explore if, how and to what extent catchment physiographical properties and hydrological states may eventually control - by dampening or enhancing - (i) mean transfer time and (ii) magnitude of hydrological responses in case of extreme precipitation events. 


\subsection{Hypotheses}

Based on the current state-of-the-art on flash flood type events in Central Europe and MA regions, as well as on our recent findings on bedrock geology controls on fundamental catchment functions, we hypothesize that:

- Catchment bedrock geology is influencing - equally to what has been found for mean summer and winter runoff flood hydrograph characteristics proper to intense summer storm events, such as typically found in the MA;

- Initial catchment storage - as translated by groundwater levels and soil moisture - alongside vegetation growing state, are important factors, controlling both the response time and the damping effect of the catchment, eventually worsening or mitigating the devastating potential of a flash flood.

\subsection{Methodology}

For testing our hypotheses, we compare the runoff transfer time distribution between two nested catchments in the Ernz Blanche basin (Luxembourg) - an area that has recently experienced several flash flood events. These two catchments have almost equal surface area, similar elevation ranges and hydrological distances, while their bedrock geology is very different. This makes them suitable candidates for comparing transfer time distributions. We do so by applying a unit hydrograph model which enables the calculation of a transfer time distribution (TTD) irrespective of the rainfall distribution.

In section 2, we present our study area and data. In section 3, we introduce the catchments, the studied events, the applied unit hydrograph model, as well as the comparative features and the statistical tools used for characterizing the TTDs. In Section 4 we describe the validation of the unit hydrograph model and present the related results. In section 5 we discuss the differences in TTDs between catchments and seasons.

\section{Study area and hydrological events}

\subsection{The Ernz Blanche catchment}

The elongated Ernz Blanche catchment (102 km², approximatively $22.5 \mathrm{~km}$ long, $4.5 \mathrm{~km}$ wide) is located in eastern Luxembourg (Western Central Europe). This mesoscale catchment is part of the eastern limit of the sedimentary Paris basin -

120 also called the Gutland area - where layers of (permeable) sandstone alternate with (less permeable) marls (Wrede et al, 2015). The elevation ranges between $190 \mathrm{~m}$ and $420 \mathrm{~m}$.

The local climate is dominated by westerly atmospheric circulation and temperate air masses from the Atlantic (Pfister, Humbert \& Hoffmann, 2000). Seasonal differences in air temperature measured over the period 1971-2000 range from 3.8 ${ }^{\circ} \mathrm{C}$ in winter (from October to March) to $14.3^{\circ} \mathrm{C}$ in summer (from April to September) (Pfister et al, 2017). Average annual precipitation in the catchment is $800 \mathrm{~mm} . \mathrm{yr}^{-1}$. The studied period ( $1^{\text {st }}$ August $2019-1^{\text {st }}$ August 2020) was rather wet with an 
average of $910 \mathrm{~mm}$ of rainfall. The spatial distribution of precipitation follows the topography, with annual rainfall totals decreasing from $950 \mathrm{~mm}$ on the high elevated plateaus to $810 \mathrm{~mm}$ around the catchment outlet (Reisdorf, Figure 1).

The Ernz Blanche catchment has been exposed to several flash flood events in the past (1958, 2016 and 2018). This area is representative of most physiographic features found in Luxembourg. With a view to study flash flood mechanistics, we have installed a multi-parameter monitoring network in June 2019, geared towards the study of extreme rainfall-runoff responses. Six stream-gauges have been installed along the $27.5 \mathrm{~km}$ long Ernz Blanche River (Douinot et al, 2019) - crossing two contrasted physiographical settings with a view to TTD comparison. In addition, four rain-gauges and soil moisture sensors were dispatched across the catchment to measure precipitation and soil water content, respectively (Figure 1). Three of the six stream-gauges - located at Koedange, Heffingen and Medernach - cut the Ernz Blanche catchment in two distinct sections: the Koedange subcatchment (KOE) and the Heffingen-Medernach section (HM). The two sections cover almost equal areas and exhibit similar elevation range and slope (table 1), but with different geological substrates. The area extending upstream of the Koedange station is almost equally split between marly terrain (middle Keuper, Km3), and the Luxembourg sandstone outcrops ( $\mathrm{Li}$ 2, table 1) which contains the groundwater table. The area extending between the Heffingen and Medernach stations mainly consists of deeply cut Luxembourg sandstone, partially overlayed by marly plateaus (Li3, table 1).

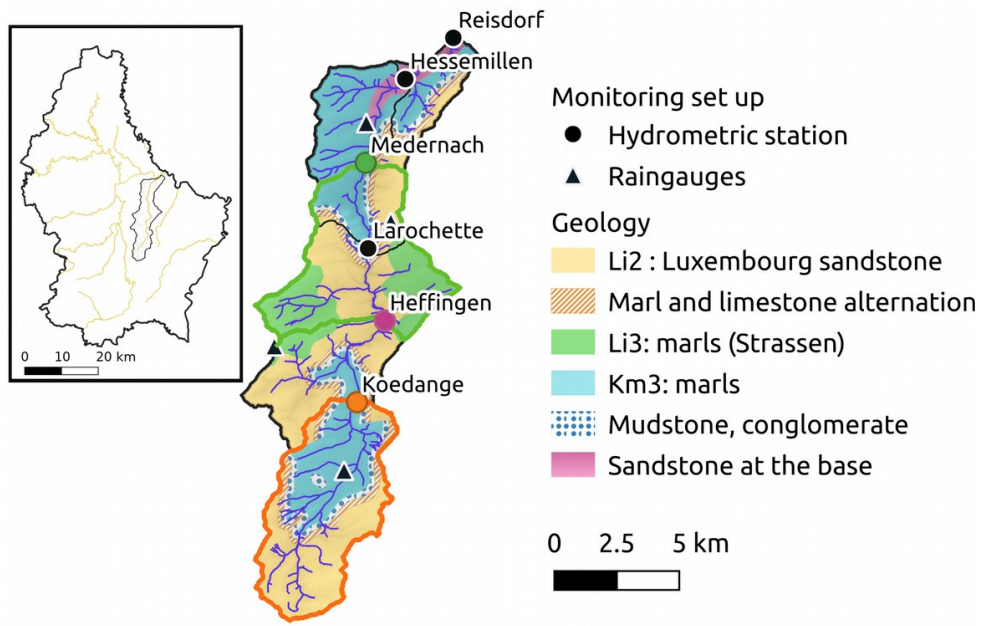

Figure 1: Ernz Blanche catchment $\left(102 \mathrm{~km}^{2}\right)$. Discharge and rainfall monitoring network; geological characteristics. The Koedange subcatchment (KOE) and Heffingen-Medernach section (HM) are highlighted with orange and green contours respectively.

Table 1: Properties of the Ernz Blanche catchment by section

\begin{tabular}{ccccccc}
\hline Catchment section & $\begin{array}{c}\text { Area } \\
{[\mathrm{km} 2]}\end{array}$ & $\begin{array}{c}\text { Elevation }[\mathrm{m}] \\
\mathrm{q}^{25 \mathrm{th}}-\mathrm{q}^{75 \mathrm{th}}\end{array}$ & $\begin{array}{c}\text { Slope [-] } \\
\mathrm{q}^{25 \mathrm{th}}-\mathrm{q}^{75 \mathrm{~h}}\end{array}$ & $\begin{array}{c}\text { Distance to the } \\
\text { outlet [km] } \\
\mathrm{q}^{25 t h}-\mathrm{q}^{75 \mathrm{th}}\end{array}$ & $\begin{array}{c}\text { Main } \\
\text { geology }\end{array}$ & $\begin{array}{c}\text { Secondary } \\
\text { geology }\end{array}$ \\
\hline Koedange subcatchment & 31.14 & $320-385$ & $0.035-0.125$ & $3.91-8.57$ & $\mathrm{Li2}(46.2 \%)$ & $\mathrm{Km} 3(41.7 \%)$ \\
\hline Heffingen - Medernach & 30.35 & $323-372$ & $0.046-0.123$ & $3.72-7.78$ & $\mathrm{Li2}(40.4 \%)$ & $\mathrm{Li3}(35.2 \%)$ \\
\hline
\end{tabular}



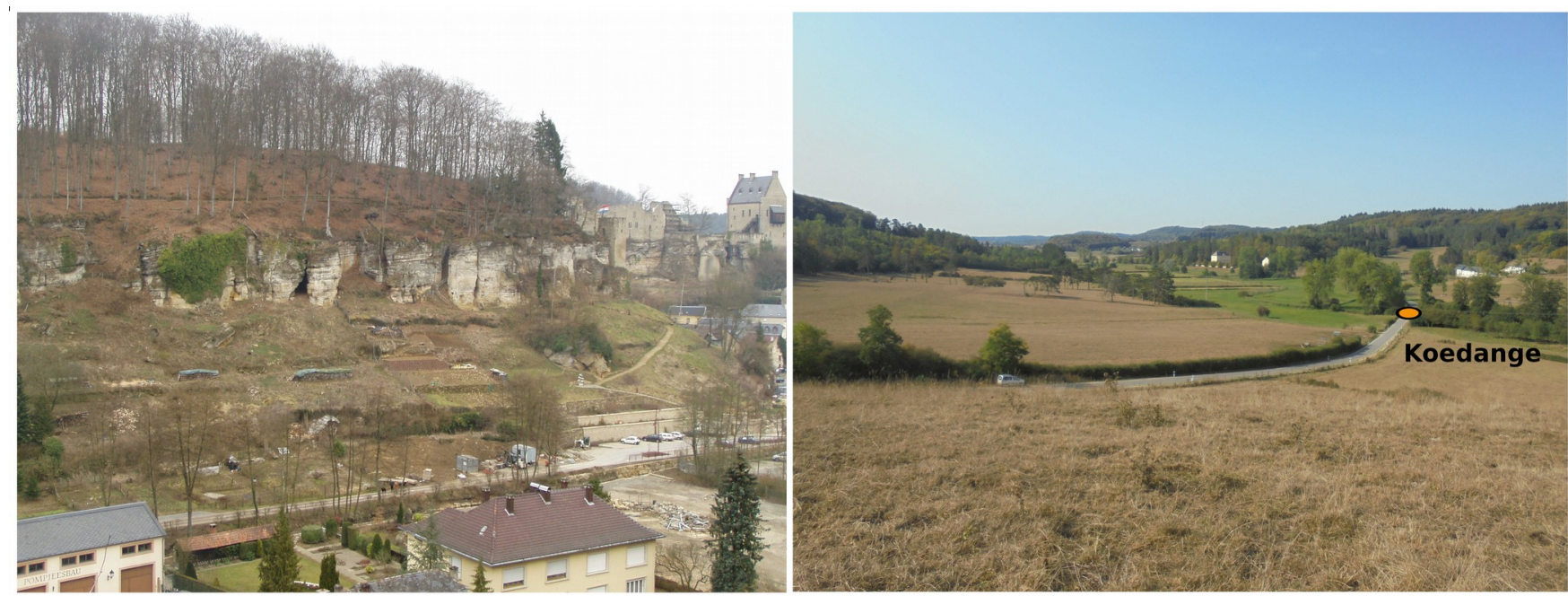

145 Figure 2: Overview of the Ernz Blanche catchment. Left: View the upstream part of the Koedange station (marked in orange). The arable land roughly corresponds to the $\mathrm{Km} 3$ geology, while the surrounding forest corresponds to the Li2 geology. Right: View of the sandstone cliffs in the White Ernz valley at Larochette (Kausch \& Maquil, 2018).
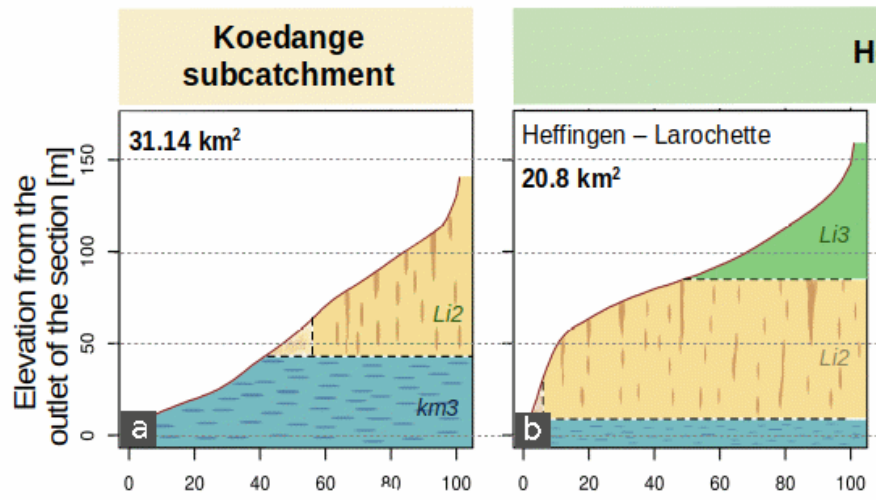

\section{Heffingen - Medernach subcatchment}

Figure 3: Geological profiles in the Ernz Blanche catchment. Elevation distribution of a) the Koedange subcatchment, b,c,d) 3 subsections of the Heffingen-Medernach area: b) the Larochette - Heffingen subsection; c) the right riverbank of the Medernach Larochette subsection; d) the left riverbank of the Medernach - Larochette subsection. Elevation is counting from the minimum elevation of each section. The geological substrates are designed according to their proportion in each section. Blue: Marls from middle Keuper (Km3); dark yellow: Luxembourg sandstone (Li2); green: Strassen marls (Li3), light brown: conglomerates, marls and limestone alteration.

The similar elevation and slope characteristics actually hide contrasted landscape features (Figure 3). In the Koedange

catchment (KOE, Figure 3-a) and on the left-handed hillslopes of the Ernz Blanche river between Medernach and Larochette (part of HM, Figure 3-d), the marly middle Keuper substrate is predominant and slopes are moderate (Figure 2, left). On the Larochette-Heffingen section (Figure 3-b) and on the right riverbank of the Medernach-Larochette section (Figure 3-c) sandstone cliffs are more prominent. The river network is deeply cut into the sandstone bedrock. As described in Kausch \& Maquil (2018): “The Luxembourg Sandstone as a whole is cut through by a nearly vertical network of primary joints, with a 
meter- to decameter-wide spacing. These joints define large blocks or slabs and influence strongly the layout of the drainage system. Joints and fissures are mostly closed on the plateaus but may be widely opened by dissolution in lower lying zones of water infiltration or by unloading along the plateau edges [...]” (Figure 2, right).

\subsection{Hydro-meteorological datasets (August 2019 - July 2020)}

\subsubsection{The monitoring network}

165 We leverage one year of rainfall and discharge measurements recorded at a 5-minute time step between $1^{\text {st }}$ August 2019 and $1^{\text {st }}$ August 2020. Rainfall has been recorded using 4 tipping bucket raingauges with an impulse of $0.2 \mathrm{~mm}$ (Campbell Kalyx, see figure 1 for the raingauge locations). The observed rainfall measurements were interpolated using the Thiessen polygon method. The water levels have been recorded using a CS475A radar sensor. The discharge rating curves were determined via 20 gauging measurements per station, all carried out within the studied year. Note that the gauging campaigns also cover the

170 two highest floods observed.

Soil humidity sensors (Campbell CS650) were installed at $20 \mathrm{~cm}$ and $50 \mathrm{~cm}$ depth next to the raingauge locations. They recorded soil humidity at a 5-minute time step in the 2 main soil textures of the catchment, namely sandy soils and clay soils. The observed soil humidity measurements were weighted according to the cover rate of each soil texture to account for their spatial variability.

\subsubsection{Selection of the rainfall-runoff events and their characteristics}

We selected 23 rainfall-runoff events (figure 4, table 2) according to the following criteria: i) the rainfall amount had to exceed $10 \mathrm{~mm}$ on the Ernz blanche in Medernach, and ii) there had to be less than 6 hours without rain within a single event. The data set covers a wide range of rainfall event durations (table 2), spanning from several summer storms having lasted a few hours (with a minimum of 6 hours) to winter events spread over several days (the maximum being 3 days). Rainfall events had their intensities ranging from significant (i.e., up to $21,7 \mathrm{~mm}$ in 1 hour) to low ( $<1.5 \mathrm{~mm}$ in 1 hour). The seasonal cycle of the soil wetness state is also well represented by our dataset, with initial soil moisture conditions spanning almost the full width of the annual distribution $\left[\mathrm{q} 1^{\text {th }}-q 99^{\text {th }}\right]$.

Due to the large range of the observed rainfall forcing and initial catchment wetness states, our one-year dataset covers a large diversity in floods. The runoff coefficients vary from $1 \%$ to $30 \%$. Note that the observed flood peaks span two orders of magnitudes. From the 23 monitored rainfall events and the subsequent discharge responses (including initial soil moisture conditions), we were able to discern two distinct patterns (Figure 4 and Figure S1 on supplementary material). The headwaters (as expressed through the Koedange and Heffingen stream gauges) consistently triggered rather attenuated hydrological responses. Further downstream, the stream gauges located downstream of Larochette exhibited a much more responsive behavioural pattern. 

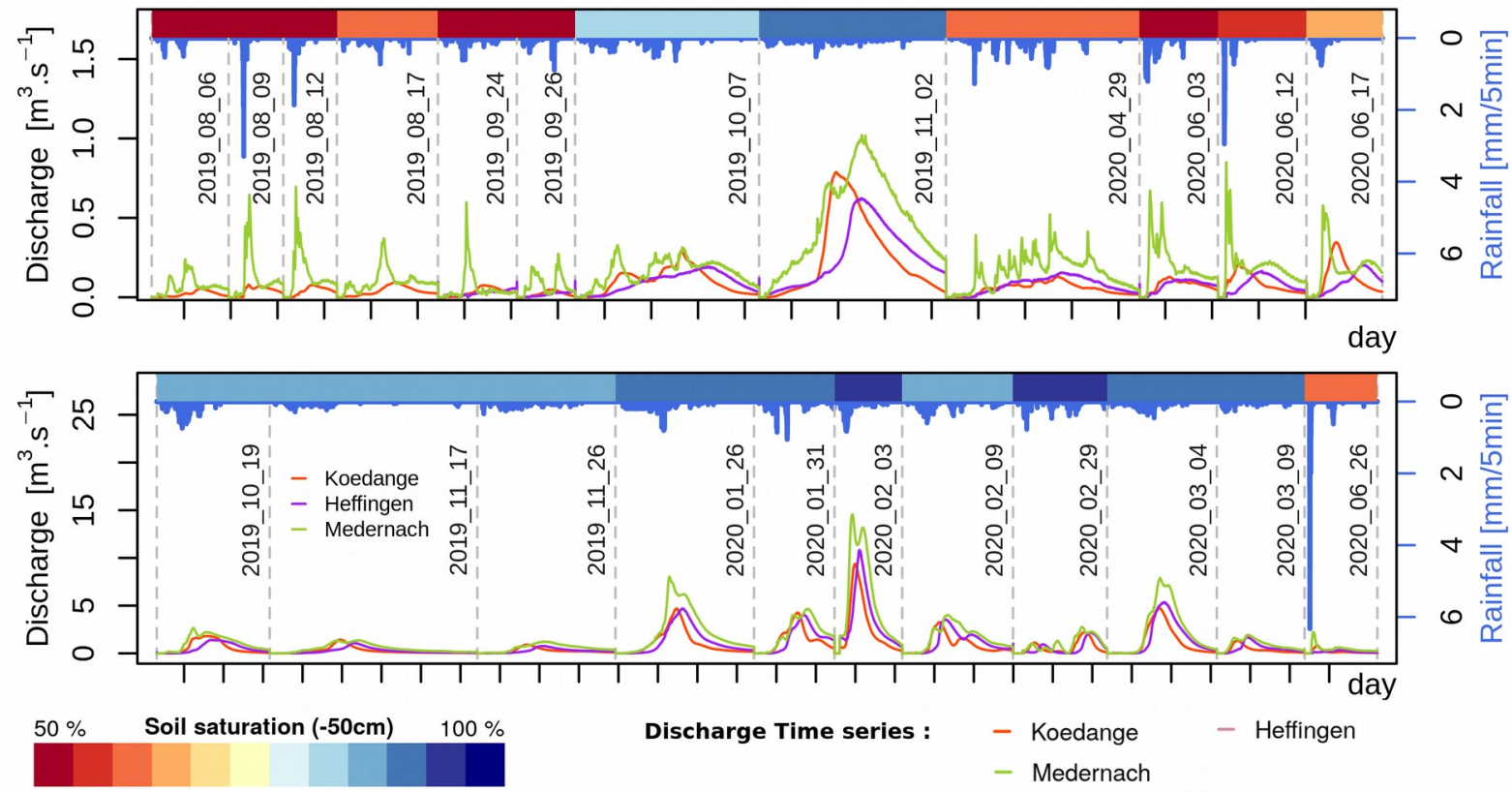

Figure 4: Overview of the events from August 2019 to August 2020. On the upper panel are presented the events with lower hydrological responses (Note: the discharge scale is different between the two panels). The color scale on the top of each panel represents the initial soil moisture state at $50 \mathrm{~cm}$ depth at the beginning of each event.

Table 2: Rainfall event properties, initial soil moisture and discharge characteristics. (*) Rainfall statistics relate to the Medernach upper catchment. (**) Initial soil moisture values correspond to the arithmetic mean of the four observed TS. (***) RC: Runoff coefficient calculated for the Medernach upper catchment; Peak discharge: arithmetic mean of peak discharge observed at Koedange and Medernach. In bold: extreme values.

\begin{tabular}{|c|c|c|c|c|c|c|c|}
\hline \multirow[b]{2}{*}{ Event } & \multicolumn{3}{|c|}{ Rainfall * } & \multicolumn{2}{|c|}{ Soil moisture** [\%] } & \multicolumn{2}{|c|}{ Runoff*** } \\
\hline & $\begin{array}{c}\text { Amount } \\
{[\mathrm{mm}]}\end{array}$ & Duration [h] & $\begin{array}{l}\text { Max. intensity } \\
{[\mathbf{m m} / \mathbf{h}]}\end{array}$ & $\begin{array}{c}-20 \mathrm{~cm} \text { in } \\
\text { depth }\end{array}$ & $\begin{array}{c}-50 \mathrm{~cm} \text { in } \\
\text { depth }\end{array}$ & RC [\%] & $\begin{array}{l}\text { Peak disch. } \\
{\left[\text { L.km } \mathbf{k m}^{-2} \cdot \mathrm{s}^{-1}\right]}\end{array}$ \\
\hline 2019/08/06 & 11.1 & 14.5 & 3.45 & 52.6 & 70.1 & 1.02 & 2.3 \\
\hline 2019/08/09 & 14.2 & 11.8 & 12.08 & 60.3 & 71.6 & 1.09 & 5.2 \\
\hline 2019/08/12 & 13.5 & 7.9 & 8.21 & 54.4 & 72.8 & 1.66 & 5.7 \\
\hline 2019/08/17 & 16.3 & 34.0 & 2.94 & 60.2 & 73.1 & 1.67 & 3.9 \\
\hline 2019/09/24 & 11.0 & 27.9 & 4.12 & 52.5 & 70.6 & 1.04 & 4.9 \\
\hline 2019/09/26 & 9.8 & 17.7 & 2.87 & 54.0 & 72.0 & 1.31 & 2.5 \\
\hline 2019/10/07 & 30.3 & 67.1 & 3.51 & 84.2 & 77.9 & 2.24 & 6.7 \\
\hline 2019/10/19 & 43.6 & 24.6 & 6.30 & 89.6 & 87.8 & 8.33 & 45.9 \\
\hline 2019/11/02 & 21.4 & 74.4 & 3.35 & 91.0 & 88.7 & 10.35 & 19.1 \\
\hline 2019/11/17 & 17.9 & 37.3 & 2.01 & 88.1 & 89.9 & 16.53 & 31.6 \\
\hline 2019/11/26 & 17.3 & 60.5 & 1.99 & 90.6 & 89.2 & 14.17 & 22.5 \\
\hline $2020 / 01 / 26$ & 35.3 & 49.7 & 6.05 & 88.1 & 89.1 & 26.04 & 125.9 \\
\hline $2020 / 01 / 31$ & 21.5 & 35.7 & 6.56 & 88.0 & 89.8 & 22.86 & 97.8 \\
\hline
\end{tabular}




\begin{tabular}{|c|c|c|c|c|c|c|c|}
\hline 2020/02/03 & 30.6 & 29.0 & 8.38 & 96.0 & 91.7 & 29.10 & 228.2 \\
\hline 2020/02/09 & 26.2 & 53.6 & 4.57 & 89.2 & 91.7 & 19.22 & 77.7 \\
\hline 2020/02/29 & 20.5 & 39.0 & 3.17 & 96.3 & 92.0 & 12.98 & 52.9 \\
\hline 2020/03/04 & 24.2 & 45.4 & 2.42 & 93.3 & 93.8 & 29.59 & 125.9 \\
\hline 2020/03/09 & 11.6 & 41.2 & 2.16 & 92.6 & 93.0 & 18.86 & 33.6 \\
\hline $2020 / 04 / 29$ & 35.2 & 69.8 & 4.48 & 57.9 & 77.6 & 2.08 & 5.4 \\
\hline 2020/06/03 & 27.3 & 19.6 & 7.88 & 52.8 & 69.6 & 1.55 & 6.3 \\
\hline 2020/06/12 & 16.6 & 16.0 & 9.74 & 60.5 & 70.1 & 2.37 & 8.7 \\
\hline 2020/06/17 & 17.2 & 13.3 & 6.21 & 67.4 & 72.4 & 2.19 & 9.2 \\
\hline $2020 / 06 / 26$ & 28.4 & 20.3 & 21.68 & 63.8 & 71.9 & 3.82 & 27.7 \\
\hline EXTREMA & 43.6 & $7.9-74.4$ & $1.99-21.68$ & $52.5-96.3$ & $69.6-93.8$ & $1.02-29.6$ & \\
\hline
\end{tabular}

\section{Methodology - the unit hydrograph model}

\subsection{Modeling the rainfall-runoff transformation with a Gamma distribution function}

We applied a simple unit hydrograph model to reproduce the hydrological responses of each rainfall forcing over each catchment section. The unit hydrograph model assumes (by definition) that each net rainfall unit has the same TTD. Note that we assume the runoff coefficient (RC) to be constant during the event.

Applying a unit hydrograph model allows for calculating a TTD independently of the rainfall distribution. Moreover, the hydrological response of the HM section can be extracted from that determined for the entire Medernach catchment. We chose the Gamma probability density function (PDF) as unit hydrograph model. The Gamma PDF enables a wide range of likelihood TTD (Hrachowitz et al, 2010), while only requiring the calibration of two parameters.

205 The Heffingen-Merdernach catchment section requires an additive modelling unit to simulate the hydraulic transfer of the discharge inflow from Heffingen. We chose a Gumbel PDF to simulate the $7.9 \mathrm{~km}$ hydraulic transfer from Heffingen to Medernach. The hydraulic transfer process is indeed linear enough to be well simulated by this function. Two unit hydrograph models and one hydraulic transfer model are applied to simulate the discharge at Koedange and Medernach stations as described in equations 1 and 2.

$Q(t)_{\text {Koedange }}=\int_{0}^{t} R_{\text {Koedange }}(\tau) \mathrm{Ga}_{\mu, \theta}^{R}(t-\tau) \mathrm{d} \tau$

$Q(t)_{\text {Medernach }}=\int_{0}^{t} R_{\text {Heffingen - Medernach }}(\tau) \mathrm{Ga}_{\mu, \theta}^{R}(t-\tau) \mathrm{d} \tau+\int_{0}^{t} Q_{\text {Heffingen }}(\tau) \mathrm{Gu}_{\mu, \theta}^{Q}(t-\tau) d$

With: $R_{x}(t)$ is the net rainfall amount after infiltration on the $\mathrm{X}$ (either KOE or HM) catchment section; $\mathrm{Q}_{\text {Heffingen }}(t)$ is the discharge observed at Heffingen station; $G a_{\mu, \theta}^{R}(t)$ is the Gamma PDF modelling the transfer time distribution of 
$R_{x}(t) ; G u_{\mu, \theta}^{Q}(t)$ is the Gumbel PDF modelling the hydraulic transfer of the catchment inflow at Heffingen. $(\mu, \theta)$ are the 215 model parameters.

Note that the Gamma and the Gumbel PDF are described in equations 3 and 4, respectively:

$\mathrm{Ga}_{\mu, \theta}(t)=\frac{1}{\Gamma(\mu)} e^{\frac{-t}{\theta}} \cdot t^{\mu-1}$ where $\Gamma(\mu)$ is the gamma function

$\mathrm{Gu}_{\mu, \theta}(t)=\frac{1}{\theta} \cdot \exp \left(\frac{-t-\mu}{\theta}+\mathrm{e}^{\frac{-t-\mu}{\theta}}\right)$

For each event, the net rainfall amount after infiltration $-R_{x}{ }^{\text {evt } \_}(t)-$ is assessed from the observed runoff coefficient $\left(\mathrm{RC}_{\mathrm{x}}{ }_{\mathrm{e}}^{\text {evt }-i}\right)$ as described in equation 5,6,7.

$\mathrm{RC}_{\mathrm{MH}}^{\mathrm{evt}-i}=\frac{\int_{t_{\text {init }}}^{t_{\text {end }}} Q_{\text {Medernach }}(t)-Q_{\text {Medernach }}\left(t_{\text {init }}\right) \mathrm{dt}-\int_{t_{\text {init }}}^{t_{\text {end }}} Q_{\text {Heffingen }}(t)-Q_{\text {Heffingen }}\left(t_{\text {init }}\right) d t}{\sum_{t_{\text {init }}}^{t_{\text {end }}} P_{\text {Medernach - Heffingen }}(t)}$

$\mathrm{RC}_{K}^{\mathrm{evt}-i}=\frac{\int_{t_{\text {init }}}^{t_{\text {end }}} Q_{\text {Koedange }}(t)-Q_{\text {Koedange }}\left(t_{\text {init }}\right) \mathrm{dt}}{\sum_{t_{\text {init }}}^{t_{\text {end }}} P_{\text {Koedange }}(t)}$

$R_{x}^{\mathrm{evt}-i}(t)=\mathrm{RC}_{x}^{\mathrm{evt}-i} \cdot P_{x}(t)$

With: $P_{x}(t)$ and $\mathrm{R}_{\mathrm{x}}(\mathrm{t})$ is the rainfall amount and the net rainfall amount respectively observed in the $X$ (KOE or HM)

225 catchment section; $t_{\text {init }}$ and $t_{\text {end }}$ the start and the end time of the event evt-i, and $R C_{x}^{e v t, i}$ the observed runoff coefficient during the event evt-i in the $X$ catchment section.

We relied on a Monte Carlo analysis with 2000 parameter sets for calibrating the models. The models' parameter $(\mu, \theta)$ ranges are presented in table 3. They have been chosen according to prior rough assessments of the median transfer time (period between the median times of the net rainfall and the runoff distribution, see supplementary material S2) and the time lag between flood peaks at Medernach and Heffingen (for the hydraulic model).

Table 3: Model's parameter ranges

\begin{tabular}{|lc|c|}
\hline & $\mu$ & $\theta$ \\
\hline Koedange model (Gamma PDF) & $1-18$ & $0.1-15$ \\
\hline Heffingen-Medernah model (Gamma PDF) & $0.1-16$ & $0.1-15$ \\
\hline Hydraulic model (Gumbel PDF) & $0.1-4.5$ & $0.1-5$ \\
\hline
\end{tabular}


For our event-based calibration, we used the Root Mean Square Error (RMSE) as objective function. It enables to focus the calibration on the high flows and their timing (unlike an objective set on the flow duration curve for example). From the calibration results, we first select the 50 best simulations. We then gradually reduce the number of acceptable simulations, as the variation of the RMSE scores among this likelihood subset exceeds $10 \%$ of the mean discharge. This limit ensures homogeneous modelling results within the subset, so that they could consequently be equally considered. (Note that a weighting process according to the RMSE could also have been chosen for similar results).

\subsection{Properties of the transfer time distributions and correlation analysis}

240 From the event-based calibration, we obtain a TTD set for each event over each catchment section. We opted for comparing the different TTD sets by defining three properties (Figure 5):

- $\quad$ TTD50: the median transfer time [h], i.e. the $50^{\text {th }}$ percentile of the TTD;

- TTDpk: the flow peak lag time [h], i.e. the time where the TTD is at its maximum;

- VOL1h: the runoff response concentration in one hour [\% of the total runoff volume].

245 TTD50 is representative of the time lag between the hyetograph and hyetogram barycenter, which characterizes the average transfer speed of a catchment. TTDpk and VOL1H characterize the dominant transfer speed and how the transferred water volume is more or less concentrated around the flood peak. The two latter properties are of first order of interest to characterize the ability of a catchment to generate fast and high magnitude floods, and eventually flash floods.

We analyze the variation of the TTD properties according to the different rainfall and catchment properties. Among a larger number of rainfall properties, we chose: the rainfall amount (Rcumul [mm]), the rainfall duration (Rduration [h]), the maximum rainfall intensity in 1 hour (I1h $\left[\mathrm{mm} \cdot \mathrm{h}^{-1}\right]$ ), the mean rainfall intensity (Imean $\left[\mathrm{mm} \cdot \mathrm{h}^{-1}\right]$ ). Those statistics were picked from a larger number of options, appearing during the analysis to be the most significant. The catchment state before each hydrological event is described using: the soil moisture at $-20 \mathrm{~cm}$ depth (SWC20 [\%]), and at $-50 \mathrm{~cm}$ in depth (SWC50 [\%]), the baseflow (Qbase $\left[\mathrm{m}^{3} \cdot \mathrm{km}^{-2} \cdot \mathrm{s}^{-1}\right]$ ), and the leaf area index (LAI). The latter is assessed from a Joint Research Center dataset (Pistocchi, 2015), which provides the 2002-2006 monthly average (1 $\mathrm{km}^{2}$ resolution), and which has been linearly interpolated to get daily values. The different statistics were chosen because of their availability and as they enable to characterize catchment storage state (Qbase); soil moisture states (SWCX) and vegetation state (LAI).

The dependency of the TTDs versus the rainfall and catchment state properties is studied through the non-parametric correlation scores Kendall's t (Kendall, 1938) and Hoeffding's D (Hoeffding, 1948). Both are rank-based approaches.

260 Kendall's $\tau$ assesses the possible monotonic relationship between two variables, including non-linear relations (unlike the Pearson coefficient). Hoeffding's D can detect non monotonous relationships. The statistics are calculated using Stats (3.4.4) and Hmisc (4.4-0) packages on R. 


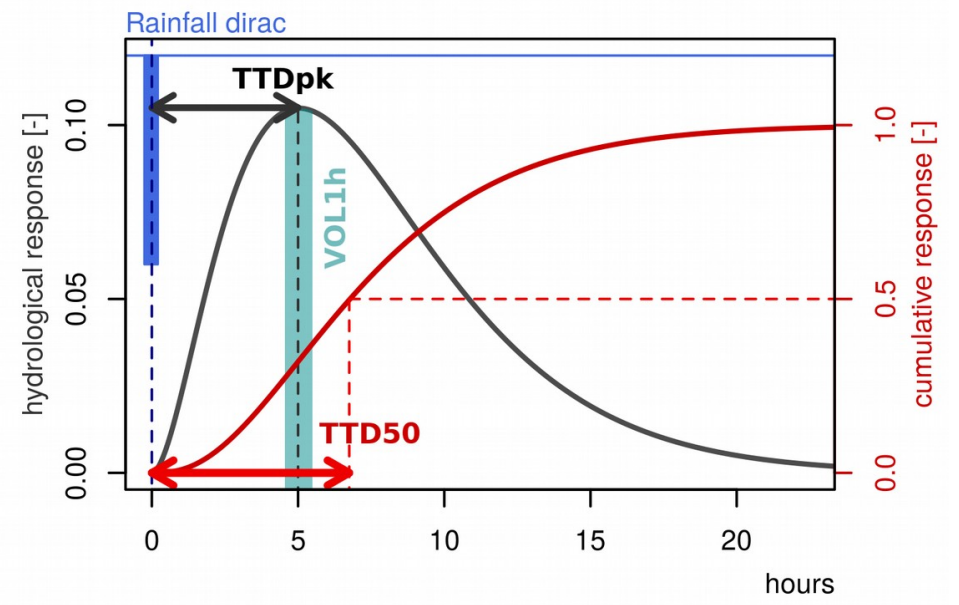

Figure 5: Illustration of the TTD properties on a unit hydrograph: TTD50, TTDpk and VOL1h.

\section{Results}

\subsection{Validation of the models}

Table 4 provides a multiple assessment of the model calibrations using the Root Mean Square Errors of the event times series (RMSE), as well as of the flow duration curve (FDC), and the Nash-Sutcliffe coefficient (NASH).

According to the Nash coefficient, the models fitted very well all events, except one on the Heffingen-Medernach section. They correspond to the smallest events in terms of rainfall amounts (table 2). Most of the RMSE scores are below 15\% of the maximum peak discharge - which is an acceptable/reasonable result - except for one events on the HeffingenMedernach section (HM) and one event on the Koedange subcatchment (KOE). The latter corresponds to one of the smallest events in terms of flood peak which make it sensitive to this assessment. The simulation for the Heffingen-Medernach section was rather poor for a 3-peaked flood event that had occurred on $29^{\text {th }}$ February 2020.

According to the flow duration curve assessment, the models show limitations for simulating two summer events with high rainfall intensity on $\mathrm{HM}$, two large winter events on KOE occurring while water storage was high but not yet at maximum levels, and one summer event with exceptionally high intensity rainfall. 
https://doi.org/10.5194/hess-2022-26

Hydrology and

Preprint. Discussion started: 28 January 2022

(c) Author(s) 2022. CC BY 4.0 License.

Table 4: Assessment of the models' calibration. Median score of the likelihood selected simulations: RMSE = Root Mean Square Error expressed as a percentage of the observed peak discharge; NASH $=$ Nash-Sutcliffe coefficient; FDC $=$ Root Mean Square Error of the flow duration curve expressed as a percentage of the mean discharge. Bad scores are highlighted in bold.

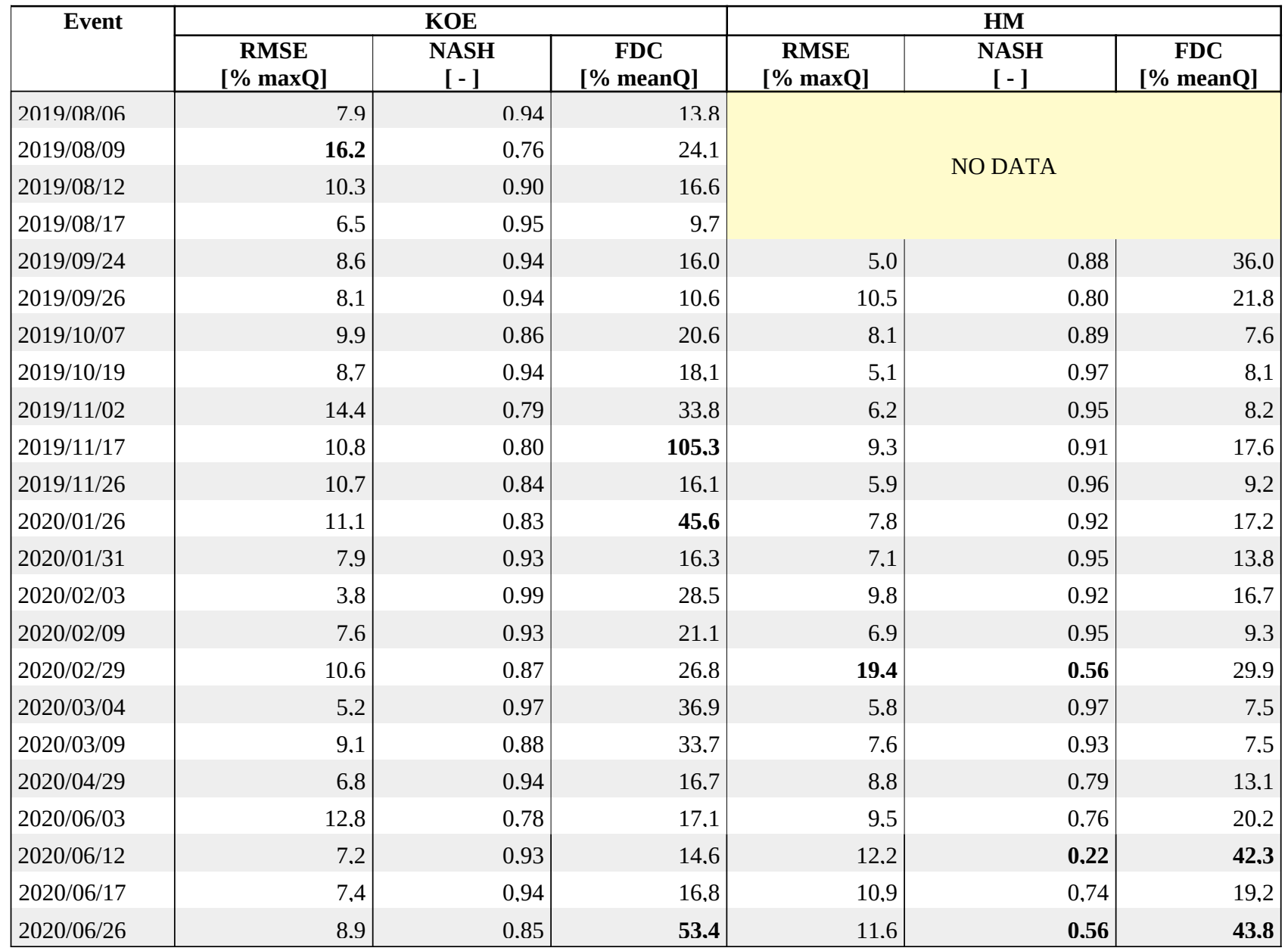

Figure 6 shows three event simulations for the KOE catchment. The events were chosen as representative of the event set simulations. The simulations of the 26/01/2020 event for the Koedange subcatchment (Fig. 6a) overestimate the rising limb and underestimate and delay the flood peak. This model limitation is observed on 6 events which are characterized by their large duration ( $>24 \mathrm{~h}$ ) and wet but not saturated soils in depth $(75 \%<$ SWC50 < $90 \%)$. The second batch of examples (Fig. 6b) shows well simulated events for KOE (i.e., all other events except the 26/06/2020), where the flood pattern is well reproduced, despite the strong heterogeneity of the rainfall. The particular case of the 26/06/2020 event is shown in figure 6c. This event consisted in 2 consecutive storms, the first one having the highest intensities of the entire time series. Here the simulations "do a compromise" for simulating both flood peak responses: the first one tends to be underestimated, while the second one is overestimated. We can also notice that only a few simulations have been validated. 

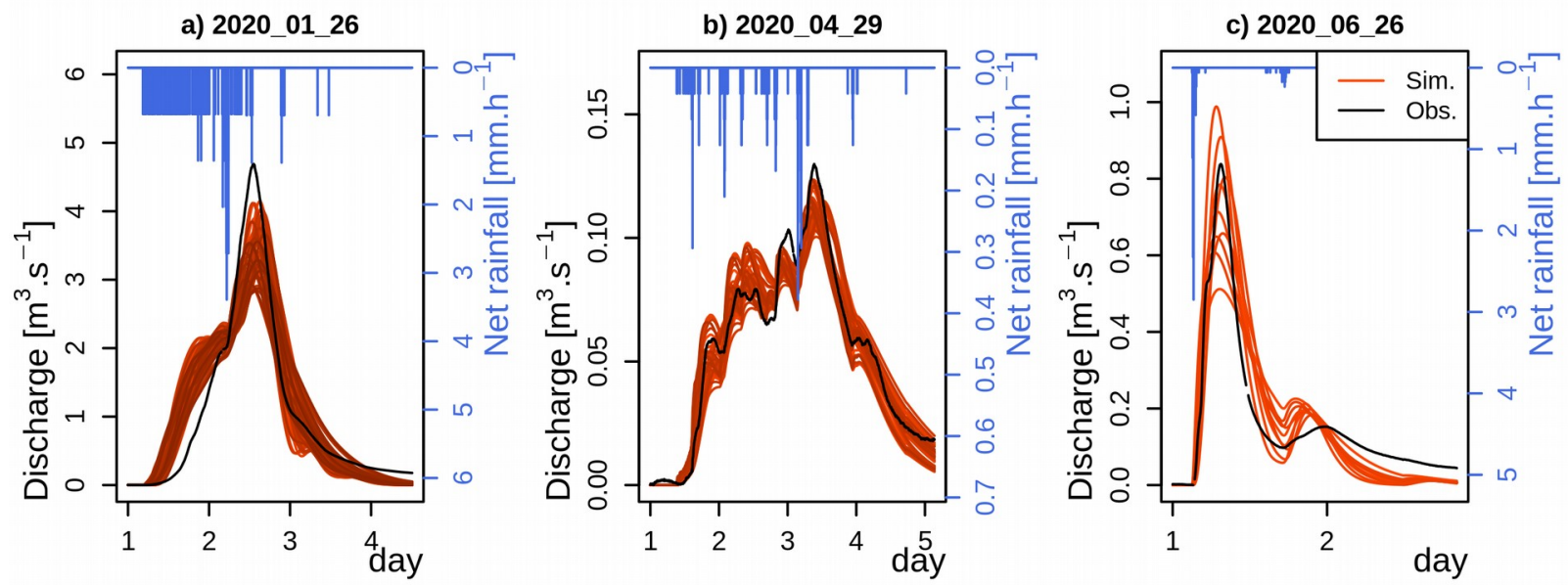

Figure 6: Examples of simulated events for the Koedange subcatchment. Event a) is representative of the winter event simulations. The displayed event on panel b) is representative of the well simulated events. On panel c) is displayed the summer event on $26 / 06 / 2020$, where the peak discharge tends to be underestimated while the second moderate event is overestimated.

Figure 7 shows three event simulations for the HM section. Similar to the KOE catchment, the simulations tend to overestimate the rising limb and to underestimate the flood peak for autumn and early winter events - but to a smaller extent (Fig. 7a). The 29/04/2020 event displayed on panel b in Figure 7 is representative of the well simulated events for the HM section. It shows how well the overall flood pattern is simulated. Note that for the HM section the instantaneous flood peaks observed during the early stages of the rising limb, are not reproduced by the simulations. Those peaks last little more than two or three 5-minute time steps, which explains why the scores are not affected by these model limitations (the errors calculated on a couple of time steps are dissolved within the overall TS assessment).
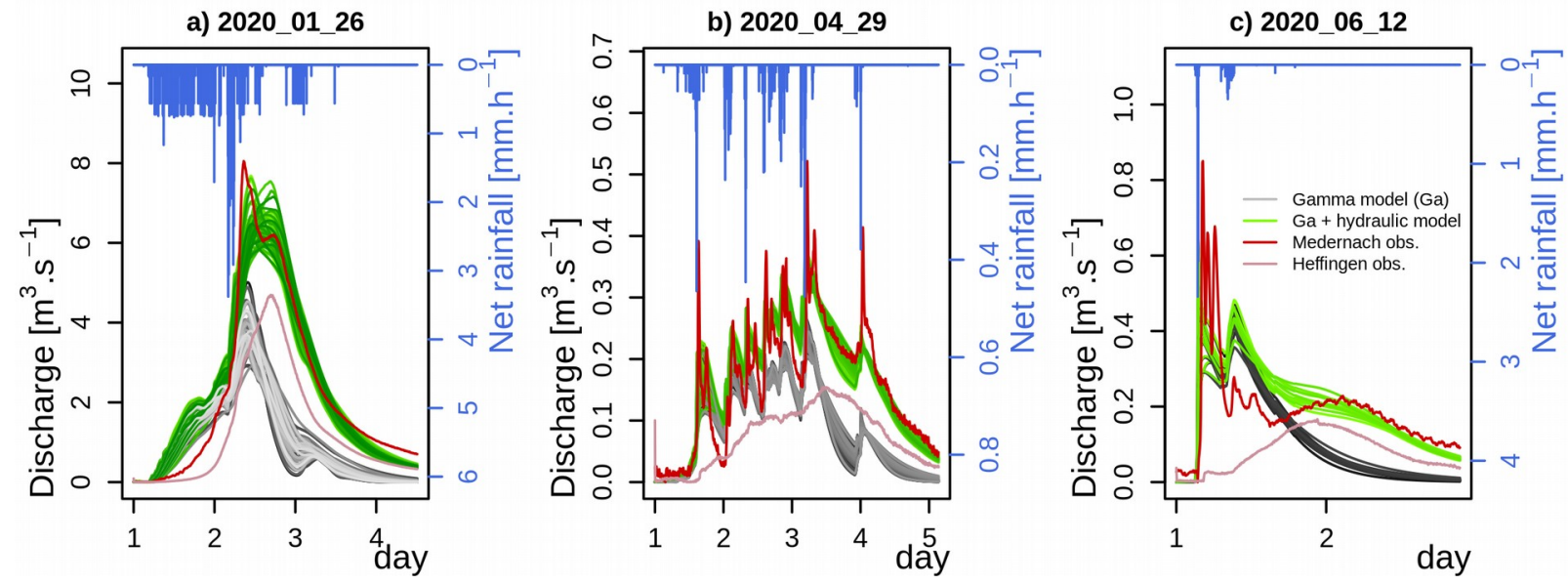

Figure 7: Examples of simulated events on the Heffingen-Medernach catchment section. The grey lines correspond to the HM runoff transfer only, while the green lines correspond to this runoff transfer + the hydraulic transfer of the Heffingen inflow. 
The 12/06/2020 event displayed in Figure 7c), alongside another small storm event that occurred on dry soils on 22/09/2019, show the models' limitations. A three-peaked observed response is caused by a high intensity and short rainfall forcing. Note that there is reportedly no error in the one peak rainfall observation.

\subsection{Comparison of Koedange and Heffingen-Medernach TTDs}

We observed a large diversity in TTDs, as obtained after the event-based calibration for the HM section and KOE catchment (Figure 8; Table 5). The median transit times (TTD50) vary between 3.3h and 17.3h, the lag time between the rainfall unit occurrence and the peak response (TTDpk) varies from $0.6 \mathrm{~h}$ to $13.6 \mathrm{~h}$ and the runoff concentration (VOL1h) varies between 4.1\% and 20\%. KOE and HM exhibit similar TTD during the November-March period, although the hydrological transfer on $\mathrm{HM}$ is almost constantly/continuously slightly quicker/faster of (-1.5h in average for TTD50) and slightly more concentrated $(+1,8 \%$ in average).

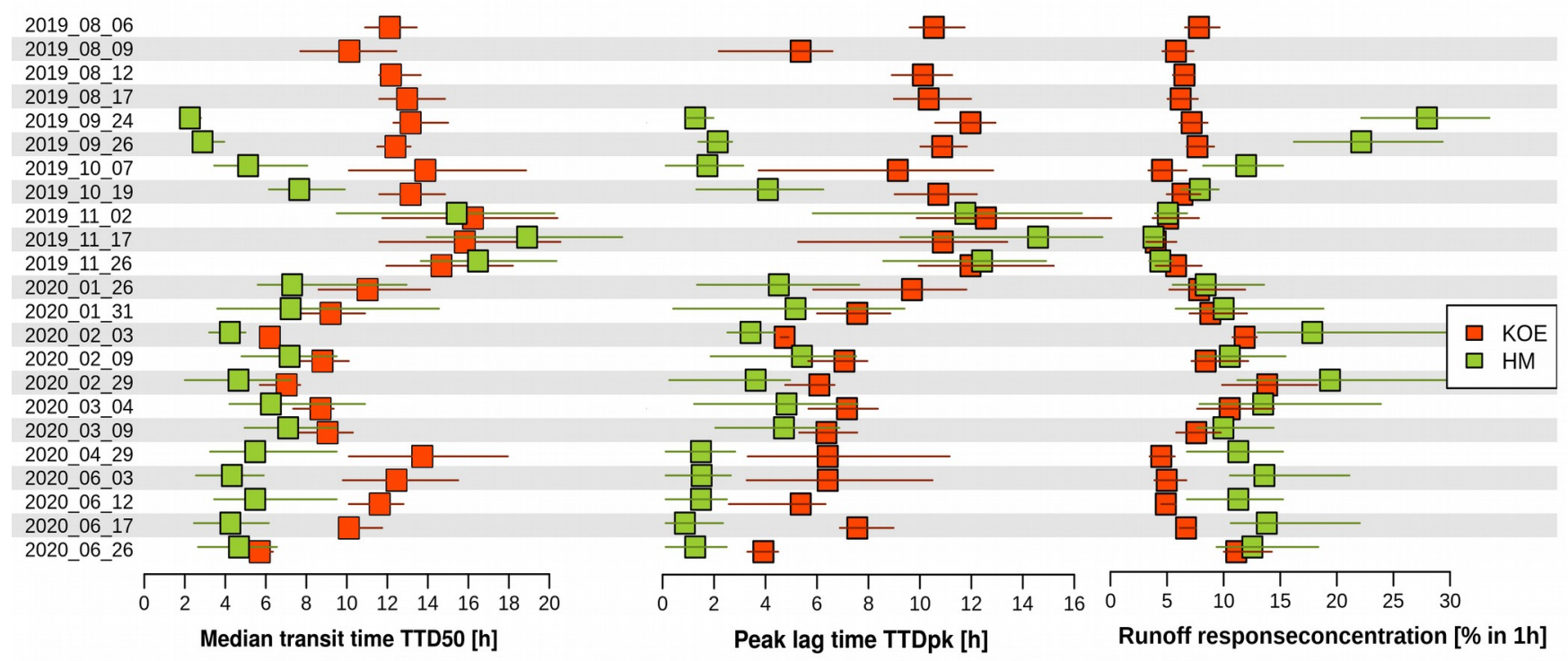

Figure 8: Properties of the simulated transfer time distributions: the median transfer time (TTD50 [h], left panel ), the peak flow lag time (TTDpk [h], center), the runoff response concentration in one hour (VOL1h [\%], right panel).

315 Significant discrepancies between both catchment sections are observed during the summer period (April-October). For the HM section, the TTD50 decreases from an average of $9.1 \mathrm{~h}$ in winter to half the value (4.6h) in summer. In contrast, the TTD50 shows less variability for the KOE catchment, and even an increase by 1.4h in summer, suggesting an opposite effect of the dry conditions on catchment responses. Eventually, TTD50 in summer is on average 2.6 times shorter for the HM section than for the KOE catchment. The peak lag times show even more contrasted values, with the average TTDpk during summer being $1.6 \mathrm{~h}$ and $8.3 \mathrm{~h}$ for the HM section and the KOE catchment respectively. We may also note the very high reactivity (i.e., short response time) of the HM section, considering its area. 
The TTD spread (VOL1H or runoff concentration) shows also different variations along the season, depending on the catchment considered. For the KOE catchment, VOL1h varies only moderately throughout the year around the small average of $6.5 \%$ ( $\sigma=2.0 \%)$. A notable exception is the February-March period, when antecedent wetness is at its highest and VOL1h then reaches $11.1 \%(\sigma=2.2 \%)$. For the HM section, the TTD equally undergoes a stretching and dampening phase between high and low antecedent wetness conditions. Between February and September VOL1h is on average $14.8 \%$ ( $\sigma=$ $2.6 \%$ ), while in autumn (October-January) the TTD are on average $7.1 \%(\sigma=2.6 \%)$.

Finally, the TTD properties show that the Koedange subcatchment is much more resilient to rainfall variability, exhibiting less variability along the season/year, and reflecting damped and delayed hydrological responses. In contrast, the high variability of the HM's TTD highlights its non-linear response, and its specific sensitivity to soil wetness, storage levels and rainfall forcing. More specifically, this catchment section appears to be vulnerable to flash flood processing as the hydrological response peak occurs really shortly after rainfall forcing and in a concentrated way during the summer period.

Table 5: Seasonal average of the TTD properties.

\begin{tabular}{|c|c|c|c|c|}
\hline & \multicolumn{2}{|c|}{ Koedange } & \multicolumn{2}{|c|}{ Medernach } \\
\hline & November - March & Abril - October & November - March & April - October \\
\hline TTD50 「h1 & $10.6 \pm 3.7$ & $12.0 \pm 2.4$ & $9.1 \pm 4.7$ & $4.6 \pm 1.4$ \\
\hline TTDpk 「h] & $8.3 \pm 2.9$ & $8.3 \pm 2.5$ & $6.7 \pm 3.4$ & $1.56 \pm 1.1$ \\
\hline VOL1h 「\%] & $8.6 \pm 3.0$ & $6.7 \pm 2.2$ & $10.4 \pm 4.8$ & $14.2 \pm 3.4$ \\
\hline
\end{tabular}

\subsection{Relating the seasonal TTD variation to the rainfall forcing and the catchment wetness state}

The correlation between the hydrological response properties (RC, TTD50, TTDpk, VOL1H), the catchment ecohydrological state (Qbase, SWC50, SWC20, LAI), and the rainfall forcing properties (Rduration, Rcumul, I1h, I15min, Imean) are studied using Kendall's $\tau$ (Kendall, 1938) and Hoeffding's $D$ (Hoeffding, 1948) correlation tests. Figure 9 illustrates the variation of the catchment state and of the rainfall properties proper to the events. Figures 10 and 11 show the Kendall's $\tau$ and Hoeffding's D correlation matrices for KOE (left panels) and HM (right panels), respectively.

For the KOE catchment, the properties of the hydrological responses show almost no significant correlation with the rainfall properties. Only the runoff coefficients appear to have a moderate non-monotonous correlation with rainfall duration. The transfer time distributions appear to be totally independent of the rainfall properties.

In contrast, both correlation tests show that the hydrological responses clearly depend on the catchment wetness state. More specifically, the runoff coefficient is highly correlated with all catchment properties - the highest correlation being with SWC20. The characteristic lag times (TTD50 and TTDpk) are linked to SWC50 and Qbase, and more specifically (with high and moderate degree) to the baseflow. Finally, the TTD damping (VOL1H) has a moderate correlation with the deep soil moisture states (SWC50).

We find slightly contrasted results for the HM section. As for the KOE catchment, the runoff coefficient is strongly linked to the catchment wetness state (more specifically to the soil moisture states SWC20 and SWC50) and less to rainfall properties. 
https://doi.org/10.5194/hess-2022-26

Preprint. Discussion started: 28 January 2022

(C) Author(s) 2022. CC BY 4.0 License.

However, the TTD variability shows an almost opposite correlation to the one observed for the KOE catchment. The TTD properties are correlated to 4 out of 5 of the studied rainfall properties. Specifically, the characteristic lag times (TTD50, TTDpk) and the response damping (VOL1H) are highly and moderately correlated, respectively, with the mean rainfall intensity (Imean). They have no correlation with the baseflow, but a strong correlation with LAI. And finally, they appear to 355 be less correlated to the soil moisture state (in HM comparing to KOE), besides TTDpk which appears to be highly correlated in a non- monotonous way with SWC50. 
https://doi.org/10.5194/hess-2022-26

Preprint. Discussion started: 28 January 2022

(c) Author(s) 2022. CC BY 4.0 License.
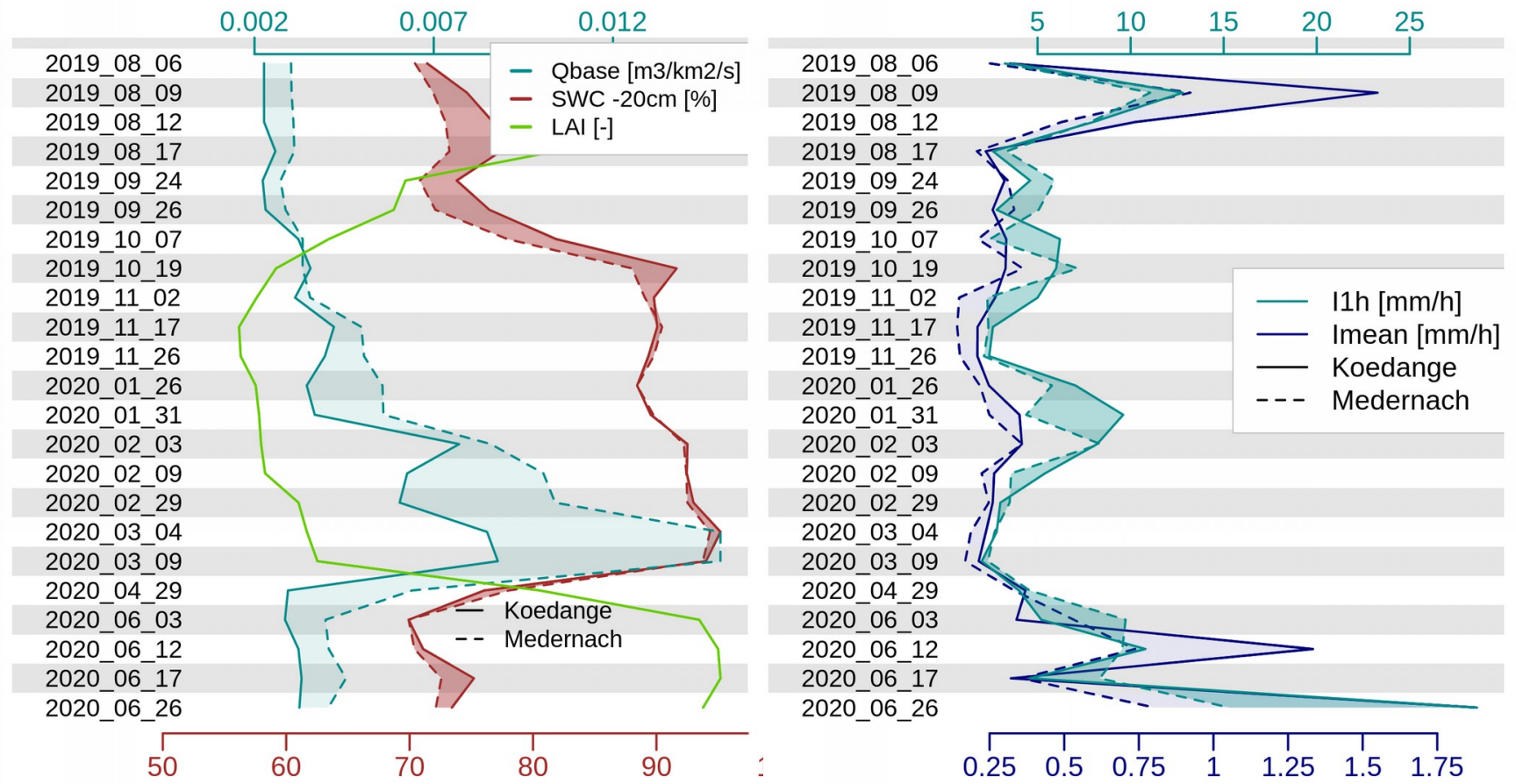

Figure 9. Left: The catchment state at the start of each event: The minimum discharge during the 7 days before the event (Qbase, $\left[\mathrm{m}^{3} \cdot \mathrm{km}^{-2} \cdot \mathrm{s}^{-1}\right]$ ), The soil moisture at $20 \mathrm{~cm}$ in depth (SWC20 [\%]) and the leaf area index (LAI [-]). Dashed lines and solid lines refer to Medernach and Koedange subcatchments respectively. Right: The rainfall properties: the maximal hourly rainfall intensity (I1h $\left[\mathrm{mm} \cdot \mathrm{h}^{-1}\right]$, light blue), the mean rainfall intensity (Imean $\left[\mathrm{mm} \cdot \mathrm{h}^{-1}\right]$, dark blue). 

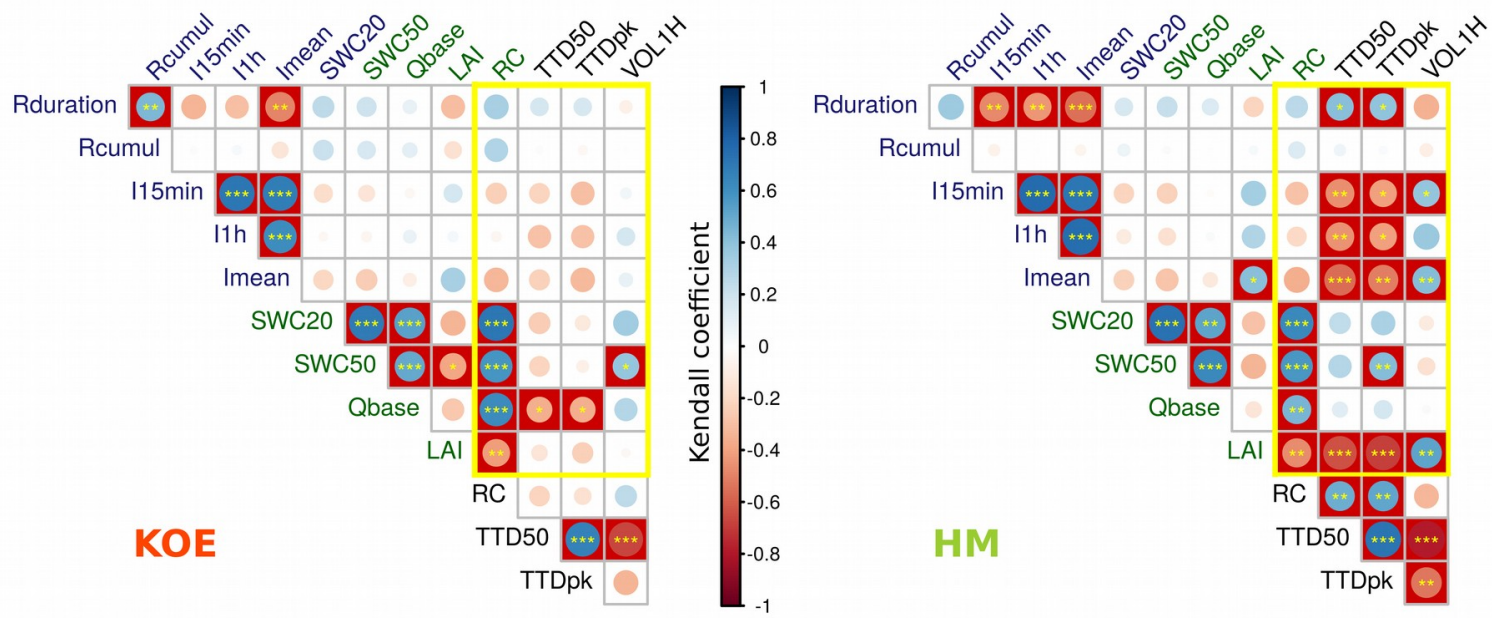

Figure 10: Kendall correlation coefficients between rainfall (blue), catchment hydrological states (green) and outlet runoff properties (black). The left and the right panels refer to KOE and HM catchment section respectively. The yellow box highlights the scores of interest for our study. The red background and the yellow stars indicate the significant correlations: $* * *$ when pvalue $<10^{-3}$; ** when $10^{-3}<$ p-value $<10^{-2}$; when $10^{-2}<$ p-value $<2.10^{-2}$.
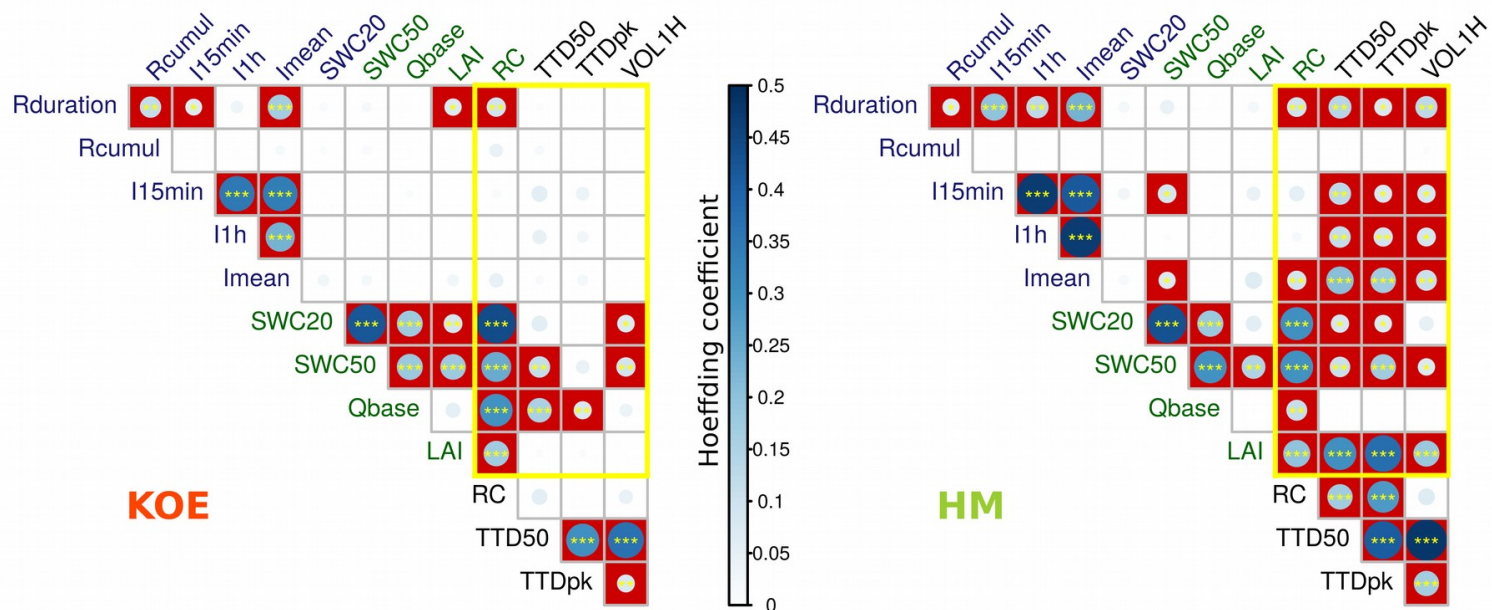

Figure 11: Hoeffding correlation coefficients between rainfall (blue), catchment hydrological states (green) and outlet runoff properties (black). The left and the right panels refer to KOE and HM catchment section respectively. The yellow box highlights the scores of interest for our study. The red background and the yellow stars indicate the significant correlations: $* * *$ when pvalue $<10^{-3}$; ** when $10^{-3}<$ p-value $<10^{-2 ;} *$ when $10^{-2}<$ p-value $<2.10^{-2}$.

\section{Discussion}

370 In our set of nested catchments with contrasted physiographic characteristics, we have targeted a better understanding of runoff generation processes during flash floods - and more specifically their respective timing. The catchment has been 
extensively instrumented for differentiating the hydrological responses of several catchment sections. We studied two sections of similar dimensions and routing distance distributions, but with different substrate and structure. The KOE catchment has a marly substrate (Km3) and moderately steep Luxembourg sandstone outcrops (Li2). The HM section has its drainage network deeply cut into the Luxembourg sandstone, with the latter being half covered by marly plateaus (Li3) with heavy clay soil. We applied a unit hydrograph model to properly extract comparable transfer time distributions of the net rainfall from the hillside to the outlet of both catchment sections. Both TTD sets relating to the 2019-2020 rainfall-runoff event database are compared and linked to the catchment hydrological state and rainfall properties.

\subsection{Insights gained on model assumptions and limitations}

The application of the unit hydrograph model has revealed its limitations for simulating some specific rainfall-runoff events in specific catchment sections. These limitations can be linked to the assumptions that the model relies on. This may eventually give us a hint to the actual mechanisms and hydrological functioning of both catchment sections.

Under wet but not yet saturated conditions, the model overestimates the rising limb of the flood wave for the KOE catchment, while it underestimates and delays the flood peak. This suggests the actual net rainfall to be rather small at the start of the event and larger towards the end. This model limitation invalidates the assumption of a constant RC. It is rather likely that RC gradually increases with rising soil wetness levels during the events. For the HM section, the limitation of a constant RC appears to be less critical. But rather than suggesting a difference in catchment behaviours, this finding is probably linked to the fact that the unit hydrograph model is only a part of the entire discharge simulation (with the other part - i.e., the hydraulic transfer, being well simulated).

390 For the KOE catchment, the flood peak of the highest 1h-rainfall intensity event (26/06/2020) is underestimated. One explanation can be that the infiltration capacity has been reached/exceeded during the short period of intensive rainfall (I1hour $=17.2 \mathrm{~mm} \cdot \mathrm{h}^{-1}$ ). Assuming a steady RC for the entire event was again not appropriate for calculating the net rainfall distribution. The peculiar TTD of this event in comparison to the other summer events corroborates a change in the partitioning of the involved hydrological processes (faster overflow, resulting in a quicker response for this event).

For the HM section, we noticed that for high intensity events, the almost instantaneous and furtive flood peaks are not well simulated. Here, we propose two non-excluding mechanisms:

- As for the KOE catchment, the infiltration capacity has been reached, causing the net rainfall to be underestimated during the time steps with high intensity rainfall. In contrast to the KOE catchment, this is the case for several events and not only for particularly high rainfall intensities. This finding suggests an overall lower infiltration capacity, which is in full agreement with the lower permeability that characterizes the clay soils of the marly plateaus. Also, the sensitivity of the TTD properties to rainfall characteristics reported in IV.3. corroborates this interpretation.

- The erratic three-peaked response observed after the impulse-like forcing of the 12.06 .2020 event highlights the spatial heterogeneity of the water transfer to the outlet. The low dispersion of the three peaks suggests distinct and 
quick flow paths, almost without damping or buffering effects on the rainfall distribution. Rather than different flow paths in a same vertical profile, it is more likely that the different flow paths correspond to different tributaries that first concentrated and routed the net rainfall. The unit hydrograph model failed here to simulate a rather complex response, as the gamma function hinted that the soil and/or the substrate would get little but enough dampening effects to inhibit the impact of the stream network layout. The HM section's behaviour was eventually similar to that of an urban or paved area.

\subsection{Conjectured hydrological processes in the studied catchment sections}

\subsubsection{The KOE catchment}

For the KOE catchment, the runoff transfer time shows little variability across the seasons. This (limited) variability appears to be monotonously (Kendall's coefficient is significant) linked to the catchment's wetness state (SWC50, Qbase). This

415 suggests that the floods are controlled by deep layer interflow processes or saturation subsurface flows. The zero and low influence of the rainfall properties and the upper soil column wetness, respectively, suggest that the critical zone is resilient to the climatic forcing, and that it enables important vertical infiltration (and water storage), which has been only exceeded during one event (see section I.1). The large flat marly terrain located downstream has a larger riparian buffering potential, leading to a low seasonal variability in the hydrological response (Iwasaki et al, 2015; Jensco et al, 2009).

420 The hydrological processes suggested here can be compared to those found in the Wollefsbach catchment $\left(4.5 \mathrm{~km}^{2}\right)$ in Luxembourg (Wrede et al, 2015; Fenicia et al, 2014). This almost 100\% marly (km3) catchment has a rather large storage capacity, considering the limited permeability of its underlying bedrock. The concept of variable contributing areas, according to soil and deep layer connectivity (wetness), is also suggested to explain the seasonality in hydrological responses. Fenicia et al. (2014) eventually found that the serial reservoir model is better suited for simulating the

425 hydrological behaviour of the catchment, which has been justified by the fact that flows are predominantly lateral. The similarities between the Koedange and Wollefsbach catchments eventually concur for suggesting the main role of the marly terrain that covers half of the downstream part of the Koedange subcatchment.

\subsubsection{The HM section}

For the HM section, the runoff transfer time shows high variability throughout the year, highlighting the influence of the 430 climate forcing and environmental states on the hydrological processes. The non-monotonous relationship (Hoeffding's coefficient is significant, but not the Kendall coefficient) between soil wetness states and the transfer time properties suggests a complex influence of the critical zone.

The longest lag times are observed in November, when soil wetness is still moderate. As the soil wetness increases through winter, the lag times gradually decrease - suggesting the onset of subsurface hydrological connectivity, similar to that 
observed for the KOE catchment. Note that both catchments exhibit a similar variability in their lag times throughout the winter period.

In summer, the lag times tend to rapidly decrease, alongside a concentration of discharge volumes around (almost instantaneously occurring) peak flows. These substantial changes in the hydrological response suggest the onset of different processes, compared to the winter season. Note that RC are one order of magnitude smaller in summer than in winter, equally suggesting a major shift in the dominating hydrological processes - corresponding in summer to the onset of surface and sub-surface contributions.

The hydrological behaviour of the HM section has similarities to those observed in catchments generating two peak hydrographs (the peaks being however alternatively seasonally explicit here). In this type of catchment, a first fast peak is commonly assumed to be generated either through saturation-excess overland flow in near-stream areas (e.g. Kirnbauer et al., 2005; Westhoff et al., 2011; Padilla et al, 2015; Martinez-Carreras et al, 2016), or via fast subsurface flow through macropores or fractures along the hillslopes (Jackisch et al., 2016; Martinez-Carreras et al, 2016; Gabrielli et al, 2012). The delayed second peak is commonly linked to groundwater processes, e.g., through a piston effect and/or an increasing connectivity to the riparian zone with the increase in GW levels / soil saturation (Onda et al, 2006).

\subsection{Specificities of the HM section's onset of quick transfer runoff during dry summer conditions}

\subsubsection{Why is there a quick transfer runoff on the HM section but not in the KOE catchment?}

In the HM section a single fast peak response to rainfall is characteristic of dry conditions. The absent - or invisible - delayed groundwater response can be related to the unsaturated soil wetness that prevents any deep infiltration below the plateau, similarly to what has been observed by Martinez-Carreras et al (2016) in a catchment with similar landscape units. Note that we cannot conclude on an absence of a flat delayed response, similar to that observed for the KOE catchment, as the consecutive overlap of the two catchment responses cannot be distinguished due to the uncertainties in discharge measurements at these low water levels.

Previous studies have shown that the organization and distribution of landscape units can control the differences in runoff responses between nested catchments (Sidle et al. 2000; McGlynn, McDonnell, Seibert, and Kendall 2004; Iwasaki et al, 2020). Iwasaki et al (2020) studied 5 catchments with similar geology, climate and vegetation, but different geomorphological layout, and concluded on the key role of the riparian area in buffering fast hillslope flow mechanisms. The contrasted hydrological response during summer in the KOE catchment - exhibiting no change in dominant hydrological processes - could be caused by:

- the larger riparian zone and the gentle slopes in the downstream part of the catchment, buffering the inflow of quick runoff (Iwasaki et al, 2015, Iwasaki et al, 2020);

465 - the less fractured Luxembourg sandstone in the KOE catchment might be less prone to trigger rapid flow paths contributions to the river. Highly fractured substrates can indeed serve as preferential pathways for significant 
subsurface flows (Graham et al, 2010). Focusing on hillslope processes, Gabrielli et al (2012) similarly showed the key role of the weathered substrate layers in the setting up of preferential lateral flow paths during storm events in the Maimai research catchment (New Zealand).

\subsubsection{Why is there quick transfer runoff on HM during the summer season and not during winter?}

Note that in principle quick transfers of water might also occur in winter in the HM section, albeit mostly hidden by larger groundwater contributions. However, a detailed scrutineering of the hydrographs did not reveal any intermediate peak flows during the rising limb of the flood hydrographs, that could have supported this conjecture. Consequently, we conclude that in summer conditions are particularly prone to fast flow paths.

475 The impact of dry conditions:

Several studies, focusing on subsurface flow celerity on hillslopes, assessed the quicker flows during dry conditions (Scaini et al, 2018; Anderson et al 2009; Asano et al, 2020), although they could not identify correlations between hillslope flow celerity and antecedent wetness conditions (Scaini, et al. 2018; Iwasaki et al, 2020). The dry conditions carry a large variability of the hillslope responses in terms of volumes and timing, which decrease during wetter conditions (Scaini et al, 2018; Bergstrom et al, 2016; Teschemacher et al, 2019). The latter observation could explain the difficulty to assess correlations with highly variable celerity at the hillslope scale.

In our study, we observed moderate correlations between response times and wetness states. We noted a time lag between the filling of the soil storage compartment (the winter plateau being reached in October) and the inhibition of rapid subsurface flows which only occur later in November. This time lag is inconsistent (because it is reversed) with the cause/consequence relationship between dry conditions and rapid flow processes that we would assume according to the previous cited studies (e.g., Scaini et al, 2018). One possible explanation is the limited spatial representativity of the soil wetness sensors - only installed on the plateaus (under grassland and with gentle slopes) and not in sloped forested areas. The only moderate correlation between response time and soil wetness suggests either the presence of deeper preferential flowpaths, or a poor representation of the soil wetness state.

490 The impact of the vegetation and the land cover:

When investigating the causes for the large variability in TTDs between events, the strongest correlation was obtained with the LAI. This rather unexpected result triggered further investigations into the role of seasonal vegetation covers on transient preferential flow paths. The hydrological network of the HM section is mostly located on steep and forested hillslopes, the latter exhibiting a pronounced seasonality in forest litter properties, including lateral permeability and hydrophobic

495 behaviour during dry conditions.

Prior studies have shown that organic litter can contribute to the onset of subsurface flows - also known as biomat flows (Sato et al, 2004; Sidle et al, 2007; Kim et al, 2014; Du et al, 2019). Forest litter (especially under deciduous trees) develops a lateral structure due to the incremental horizontal accumulation of leaves or needles. At plot scale, Sidle et al (2007) and 
Du et al (2019) showed that the biomat flow can reach up to $44.6 \%$ (46.3\%) and 12.3\% (28.5\%) of the total precipitation in pines and forest litter respectively, which was roughly three to eight times larger than hortonian flow.

Also, in addition to the lateral structure, the litter - which is particularly rich in organic matter - can develop hydrophobic properties under dry conditions (Zavala et al, 2009; Kim et al, 2014) and consequently inhibit infiltration and promote runoff (Doerr et al. 2000; Gomi et al. 2008; Gerke et al, 2015; Jeyakumar et al., 2014). For example, Miyata et al. (2009) have shown that the soil water repellency enhanced the occurrence of pseudo-surface runoff during dry conditions. Although the factor controlling the hydrophobic property are not well understood yet, the soil/litter moisture has been conjectured to be a key factor (Doerr et al. 2000; Butzen et al, 2015). Therefore, we can assume that the influence of forest floor water repellency on hydrological processes is highly seasonal.

Thus, despite the highly permeable sandy soils that cover the steep hillslopes of the HM sector, the infiltration capacity may be limited at times by the properties of the (forest) ground cover during dry conditions. The steep slopes could then potentially develop quick flow paths, eventually rapidly connected to the main river.

\section{Conclusion}

We analysed the runoff transfer time distribution over a complete year in catchments that have been recently affected by flash floods. The two studied catchments have similar size, elevation ranges and slopes, but differ in terms of geological substrates and landscape features.

515 While the variability in runoff coefficients is explained for both catchments by the soil storage dynamics, the variability in TTD has different causes. In the KOE catchment, the water transfer is essentially driven by groundwater contributions and deep soil storage dynamics (except for one summer event).

The HM section exhibits contrasted TTDs throughout the year, suggesting threshold dependent hydrological processes. More specifically, quick runoff transfers seem to dominate under dry conditions. We conjecture that the rapid flows in the HM section are not only triggered on and by its marly plateaus, but also by the hydrophobic forest litter during dry conditions. Moreover, the topographical connectivity of the steep forested slopes could develop flowpaths prone to a rapid transfer of water. The absence of a riparian zone prevents any dampening of these abrupt and massive flows in the case of extreme precipitation events.

When targeting an improvement in flash flood understanding and forecasting in Luxembourg, our results suggest that the

525 focus should be set on the development of a simulation tool adapted to catchments with physiographic characteristics similar to those of the HM sub-catchment - i.e., with fractured bedrock and limited riparian zones. The non-linear hydrological behaviour of the basin throughout the seasons requires either the implementation of a complex model that considers the nonmonotone relation between transfer velocity and soil wetness, or the set-up of a simpler model with a seasonal calibration. In general, catchments with little or no dampening zones and steep slopes require specific attention and more focused investigations on flash flood generation processes. 
More research is needed on the onset and role of infiltration processes, as well as surface and sub-surface flows, under dry conditions. The latter may lead to limited infiltration capacities on the marly plateaus, while triggering at the same time the onset of surface flows on steep forested slopes. These investigations will have to combine multiple spatial (i.e., plots, hillslopes, catchments) and temporal scales (from event to seasonal scale).

\section{Code availability}

The codes implementing the unit hydrograph model and the hydraulic transfer model can be found at the LIST GitLab (https://github.com/adouinot/TransitTimeModel, last access: 17-dec-2021).

\section{Data availability}

The rainfall and the discharge time series in this study are the property of the Luxembourg Institute of Science and 540 Technology (LIST) and can be obtained upon request from cyrille.tailliez@list.lu, after approval by LIST.

\section{Author contribution}

$\mathrm{AD}$ and LP designed the project and obtained the funding for this study. AD, JFI and CT established the experimental set up of the monitoring network and the discharge measurements. AD performed the modelling part and carried out the correlation analysis. AD, and LP jointly structured the paper, with contributions on interpretations of results from CM and JFI.

\section{Competing interests}

The authors declare that they have no conflict of interest.

\section{Acknowledgements}

This research has been carried out in the framework of a national public-private partnership funded by the National Research Fund of Luxembourg (FNR AFR PPP grant 118823575), involving POST Telecom, the 'Administration de la Gestion de 550 l'Eau' (AGE), and the Luxembourg Institute of Science and Technology (LIST). We thank POST for providing the communication technology hardware, as well as their support in the design and implementation of the experimental set-up. We thank the AGE for their support in coordinating the project, their continuous and highly valuable input during project meetings, as well as their support on securing funding through the 'Fonds pour la gestion de l'eau du Gouvernement de Luxembourg' for the acquisition of project-specific monitoring devices. 


\section{Financial support}

This research has been supported by the 'Fonds National de la Recherche du Luxembourg’ (AFR PPP grant, $\mathrm{n}^{\circ}$ 11823575), as well as through the 'Fonds pour la gestion de l'eau' of the government of Luxembourg.

\section{References}

Asano, Y., Uchida, T., and Tomomura, M.: A Novel Method of Quantifying Catchment-Wide Average Peak Propagation

560 Speed in Hillslopes: Fast Hillslope Responses are Detected During Annual Floods in a Steep Humid Catchment, Water Resources Research, 56(1), doi.org/10.1029/2019WR025070, 2020.

Anderson, A. E., Weiler, M., Alila, Y., and Hudson, R. O.: Subsurface flow velocities in a hillslope with lateral preferential flow, Water Resour. Res., 45, W11407, doi:10.1029/2008WR007121, 2009.

Berghuijs, W. R., Allen, S. T., Harrigan, S., and Kirchner, J. W.: Growing Spatial Scales of Synchronous River Flooding in

565 Europe, Geophysical Research Letters, 46(3), 1423-1428, doi.org/10.1029/2018GL081883, 2019.

Bergstrom, A., Jencso, K., and McGlynn, B.: Spatiotemporal processes that contribute to hydrologic exchange between hillslopes, valley bottoms, and streams, Water Resources Research, 52(6), 4628-4645, doi.org/10.1002/2015WR017972, 2016.

Braud, I.: Proceedings of the final ANR FloodScale workshop: multi-scale hydro-meteorological observation and modelling

570 for flash flood understanding and simulation, in: Séminaire de restitution du projet ANR Floodscale (p. 109), Aix-en Provence, France, https://hal.inrae.fr/hal-02602293, 2015.

Braud, I., Ayral, P. A., Bouvier, C., Branger, F., Delrieu, G., Dramais, G., and Vandervaere, J. P.: Advances in flash floods understanding and modelling derived from the FloodScale project in south-east France, In: 3rd European Conference on Flood Risk Management, Innovation, Implementation, Integration (FLOODrisk 2016), Vol. 7, p. 4005, Lyon, France, 575 doi.org/10.1051/e3sconf/20160704005, 2016.

Bronstaert, A., Agarwal, A., Boessenkool, B., Crisologo, I., Fischer, M., Heistermann, M., and Wendi, D.: Forensic hydrometeorological analysis of an extreme flash flood: The 2016-05-29 event in Braunsbach, SW Germany, Science of The Total Environment, 630, 977-991, https://doi.org/10.1016/j.scitotenv.2018.02.241, 2018.

Bryndal, T.: Local flash floods in Central Europe: A case study of Poland. Norsk Geografisk Tidsskrift, Norwegian Journal 580 of Geography, 69(5), 288-298, https://doi.org/10.1080/00291951.2015.1072242, 2015.

Butzen, V., Seeger, M., Marruedo, A., de Jonge, L., Wengel, R., Ries, J. B., and Casper, M. C.: Water repellency under coniferous and deciduous forest - Experimental assessment and impact on overland flow, Catena, 133, $255-265$. https://doi.org/10.1016/j.catena.2015.05.022, 2015.

EM-DAT, CRED / UCLouvain, Brussels, Belgium - www.emdat.be (D. Guha-Sapir), last access: 15 January 2021.

585 Diakakis, M., and Deligiannakis, G.: Flood fatalities in Greece: 1970-2010, Journal of Flood Risk Management, 10(1), 115123, https://doi.org/10.1111/jfr3.12166, 2017. 
Doerr, S. H., Shakesby, R. A., and Walsh, R. P. D.: Soil water repellency: Its causes, characteristics and hydrogeomorphological significance, Earth Science Reviews, 51(1-4), 33-65, https://doi.org/10.1016/S0012-8252(00)00011-8, 2000.

Douinot, A., Roux, H., Garambois, P.-A., and Dartus, D.: Using a multi-hypothesis framework to improve the understanding of flow dynamics during flash floods, Hydrology and Earth System Sciences, 22(10), https://doi.org/10.5194/hess-22-53172018, 2018.

Douinot, A., Dalla Torre, A., Martin, J., Iffly, J.-F., Rapin, L., Meisch, C., Bastian C., and Pfister, L.: Prototype of a LPWA Network for Real-Time Hydro-Meteorological Monitoring and Flood Nowcasting, In: Ad-Hoc, Mobile, and Wireless Networks (pp. 566-574), edited by: M. R. Palattella, S. Scanzio, and S. Coleri Ergen (Eds.), Lecture Notes in Computer Science, vol 11803, Springer, https://doi.org/10.1007/978-3-030-31831-4_40, 2019.

Du, J., Niu, J., Gao, Z., Chen, X., Zhang, L., Li, X., van Doorn, N. S., Luo, Z., and Zhu, Z.: Effects of rainfall intensity and slope on interception and precipitation partitioning by forest litter layer, CATENA, 172, 711-718, https://doi.org/10.1016/j.catena.2018.09.036, 2019.

600 Ducrocq, V., Braud, I., Davolio, S., Ferretti, R., Flamant, C., Jansa, A., Kalthoff, N., Richard, E., Taupier-Letage, I., Ayral, P., Belamari, S., Berne, A., Borga, M., Boudevillain, B., Bock, O., Boichard, J., Bouin, M., Bousquet, O., Bouvier, C., Chiggiato, J., Cimini, D., Corsmeier, U., Coppola, L., Cocquerez, P., Defer, E., Delanoë, J., Di Girolamo, P., Doerenbecher, A., Drobinski, P., Dufournet, Y., Fourrié, N., Gourley, J. J., Labatut, L., Lambert, D., Le Coz, J., Marzano, F. S., Molinié, G., Montani, A., Nord, G., Nuret, M., Ramage, K., Rison, W., Roussot, O., Said, F., Schwarzenboeck, A., Testor, P., Van Baelen, J., Vincendon, B., Aran, M., and Tamayo, J.: HyMeX-SOP1: The Field Campaign Dedicated to Heavy Precipitation and Flash Flooding in the Northwestern Mediterranean, Bulletin of the American Meteorological Society, 95, 7, 1083-1100, https://doi.org/10.1175/BAMS-D-12-00244.1, 2014.

Fenicia, F., Kavetski, D., Savenije, H. H. G., Clark, M. P., Schoups, G., Pfister, L., and Freer, J.: Catchment properties, function, and conceptual model representation: is there a correspondence?, Hydrological Processes, 28(4), 2451-2467, 610 https://doi.org/10.1002/hyp.9726, 2014.

Freer, J., McDonnell, J. J., Beven, K. J., Peters, N. E., Burns, D. A., Hooper, R. P., Aulenbach, B., and Kendall, C.: The role of bedrock topography on subsurface storm flow, Water Resources Research, 38(12), 10.1029/2001WR000872, 2002.

Gabrielli, C. P., McDonnell, J. J., and Jarvis, W. T.: The role of bedrock groundwater in rainfall-runoff response at hillslope and catchment scales, Journal of Hydrology, 450-451, 117-133, https://doi.org/10.1016/j.jhydrol.2012.05.023, 2012.

615 Gaume, E., Borga, M., Llassat, M. C., Maouche, S., Lang, M., and Diakakis, M.: Mediterranean extreme floods and flash floods. In: The Mediterranean Region under Climate Change. A Scientific Update, IRD Editions, pp. 133-144, https://hal.archives-ouvertes.fr/hal-01465740, 2016.

Gerke, K. M., Sidle, R. C., and Mallants, D.: Preferential flow mechanisms identified from staining experiments in forested hillslopes, Hydrological Processes, 29(21), 4562-4578, https://doi.org/10.1002/hyp.10468, 2015. 
620 Gomi, T., Sidle, R. C., Ueno, M., Miyata, S., and Kosugi, K.: Characteristics of overland flow generation on steep forested hillslopes of central Japan, Journal of Hydrology, 361(3-4), 275-290, https://doi.org/10.1016/j.jhydrol.2008.07.045, 2008.

Graham, R. C., Rossi, A. M., and Hubbert, K. R.: Rock to regolith conversion: Producing hospitable substrates for terrestrial ecosystems, GSA Today, 20(2), 4-9., doi:10.1130/GSAT57A.1, 2010.

Hoeffding, W.: A Non-Parametric Test of Independence. Ann. Math. Statist., 19(4), 546-557, 625 https://doi.org/10.1214/aoms/1177730150, 1948.

Hrachowitz, M., Soulsby, C., Tetzlaff, D., Malcolm, I. A., and Schoups, G.: Gamma distribution models for transit time estimation in catchments: Physical interpretation of parameters and implications for time-variant transit time assessment, Water Resources Research, 46(10), https://doi.org/10.1029/2010WR009148, 2010.

Iwasaki, K., Katsuyama, M., and Tani, M.: Contributions of bedrock groundwater to the upscaling of storm-runoff generation processes in weathered granitic headwater catchments, Hydrological Processes, 29(6), 1535-1548, https://doi.org/ 10.1002/hyp.10279, 2015.

Iwasaki, K., Katsuyama, M., and Tani, M.: Factors affecting dominant peak-flow runoff-generation mechanisms among five neighbouring granitic headwater catchments, Hydrological Processes, 34(5), 1154-1166, https://doi.org/10.1002/hyp.13656, 2020.

635 Jackisch, C., Angermann, L., Allroggen, N., Sprenger, M., Blume, T., Weiler, M., Tronicke, J., and Zehe, E.: In situ investigation of rapid subsurface flow: Identification of relevant spatial structures beyond heterogeneity, Hydrology and Earth System Sciences Discussion, http://dx.doi.org/10.5194/hess-2016-190, 2016.

Jencso, K. G., McGlynn, B. L., Gooseff, M. N., Wondzell, S. M., Bencala, K. E., and Marshall, L. A.: Hydrologic connectivity between landscapes and streams: Transferring reach- and plot-scale understanding to the catchment scale,

640 Water Resources Research, 45(4), doi.org/10.1029/2008WR007225, 2009.

Jeyakumar, P., Müller, K., Deurer, M., van den Dijssel, C., Mason, K., Le Mire, G., and Clothier, B.: A novel approach to quantify the impact of soil water repellency on run-off and solute loss, Geoderma, vol 221-222, pp 121-130, https://doi.org/ 10.1016/j.geoderma.2014.01.008, 2014.

Kausch, B., and Maquil, R.: Landscapes and Landforms of the Luxembourg Sandstone, Grand-Duchy of Luxembourg, in:

645 Landscapes and Landforms of Belgium and Luxembourg, edited by: A. Demoulin, Springer International Publishing, Netherlands, 1st ed., pp. 43-62, https://doi.org/10.1007/978-3-319-58239-9, 2018.

Kendall, M. G.: A new measure of rank correlation, Biometrika, 30(1/2), 81-93, 1938.

Kim, J. K., Onda, Y., Kim, M. S., and Yang, D. Y.: Plot-scale study of surface runoff on well-covered forest floors under different canopy species, Quaternary International, 344, 75-85, https://doi.org/10.1016/j.quaint.2014.07.036, 2014.

650 Kirnbauer, R., Blöschl, G., Haas, P., Müller, G., and Merz, B.: Identifying Space-time Patterns of Runoff Generation: A Case Study from the Löhnersbach Catchment, Austrian Alps, in: Global Change and Mountain Regions: An Overview of Current Knowledge, edited by: U. M. Huber, H. K. M. Bugmann, and M. A. Reasoner, Springer, Netherlands, pp. 309-320, https://doi.org/10.1007/1-4020-3508-X_31, 2005. 
Llasat, M. C., Marcos, R., Turco, M., Gilabert, J., and Llasat-Botija, M.: Trends in flash flood events versus convective precipitation in the Mediterranean region: The case of Catalonia, Journal of Hydrology, 541, 24-37, https://doi.org/10.1016/j.jhydrol.2016.05.040, 2016.

Marchi, L., Borga, M., Preciso, E., and Gaume, E.: Characterisation of selected extreme flash floods in Europe and implications for flood risk management, Journal of Hydrology, 394(1-2), 118-133, http://dx.doi.org/10.1016/j.jhydrol.2010.07.017, 2010.

Martínez-Carreras, N., Hissler, C., Gourdol, L., Klaus, J., Juilleret, J., Iffly, J. F., and Pfister, L.: Storage controls on the generation of double peak hydrographs in a forested headwater catchment, Journal of Hydrology, 543, 255-269, https://doi.org/10.1016/j.jhydrol.2016.10.004, 2016.

Massari, C., Camici, S., Ciabatta, L., Penna, D., Marra, A. C., and Panegrossi, G.: Chapter 8 - Floods in the Mediterranean area: The role of soil moisture and precipitation, in: Water resources in Mediterranean region, edited by: M. Zribi, L. Brocca,

665 Y. Tramblay, and F. Molle, Elsevier, pp. 191-218, https://doi.org/https://doi.org/10.1016/B978-0-12-818086-0.00008-X, 2020.

McGlynn, B. L., McDonnell, J. J., Seibert, J., and Kendall, C.: Scale effects on headwater catchment runoff timing, flow sources, and groundwater-streamflow relations, Water Resources Research, 40(7), https://doi.org/10.1029/2003WR002494, 2004.

670 Miller, D. J., and Dunne, T.: Topographic perturbations of regional stresses and consequent bedrock fracturing, Journal of Geophysical Research: Solid Earth, 101(B11), 25523-25536, https://doi.org/10.1029/96JB02531, 1996.

Miyata, S., Kosugi, K., Gomi, T., and Mizuyama, T.: Effects of forest floor coverage on overland flow and soil erosion on hillslopes in Japanese cypress plantation forests, Water Resources Research, 45(6), https://doi.org/10.1029/2008WR007270, 2009.

675 Molnar, P.: Interactions among topographically induced elastic stress, static fatigue, and valley incision. Journal of Geophysical Research: Earth Surface, 109(F2), https://doi.org/10.1029/2003JF000097, 2004.

Onda, Y., Tsujimura, M., Fujihara, J., and Ito, J.: Runoff generation mechanisms in high-relief mountainous watersheds with different underlying geology, Journal of Hydrology, 331(3), 659-673, https://doi.org/10.1016/j.jhydrol.2006.06.009, 2006.

Padilla, C., Onda, Y., and Iida, T.: Interaction between runoff - bedrock groundwater in a steep headwater catchment underlain by sedimentary bedrock fractured by gravitational deformation, Hydrological Processes, 29(20), 4398-4412, https://doi.org/10.1002/hyp.10498, 2015.

Payrastre, O., NAULIN, J. P., Nguyen, C. C., and Gaume, E.: Analyse hydrologique des crues de juin 2010 dans le Var, IFSTTAR - Institut Français des Sciences et Technologies des Transports, de l'Aménagement et des Réseaux, 33p, hal01272025, 2012.

685 Pereira, S., Diakakis, M., Deligiannakis, G., and Zêzere, J. L.: Comparing flood mortality in Portugal and Greece (Western and Eastern Mediterranean), International Journal of Disaster Risk Reduction, 22, 147-157, https://doi.org/10.1016/j.ijdrr.2017.03.007, 2017. 
Pfister, L., Humbert, J., and Hoffmann, L.: Recent Trends in Rainfall-Runoff Characteristics in the Alzette River Basin, Luxembourg, Climatic Change, 45(2), 323-337, https://doi.org/10.1023/A:1005567808533, 2000.

Pfister, L., Martínez-Carreras, N., Hissler, C., Klaus, J., Carrer, G. E., Stewart, M. K., and McDonnell, J. J.: Bedrock geology controls on catchment storage, mixing, and release: A comparative analysis of 16 nested catchments, Hydrological Processes, 31(10), 1828-1845, https://doi.org/10.1002/hyp.11134, 2017.

Pfister, L., Bastian, C., Faber O., Gölhausen, D., Hostache R., Iffly J.F., Matgen P., Meisch C., Minette F., Patz, N., and Trebs, I.: La crue éclair du 22 juillet 2016 dans la région de Larochette : Etude mécanistique et fréquentielle, LIST, Luxembourg, 20 pages, https://eau.gouvernement.lu/dam-assets/publications/crue-\%C3\%A9clair-du-22-juillet-2016/1812LIST-BrochureCrueEclair.pdf, 2018.

Pfister, L. Bastian, C., Douinot A., Gilbertz, C., Göhlhausen, D., Hostache R., Iffly J.F., Matgen P., Meisch C., Minette F., and Patz, N.: Etude mécanistique et fréquentielle des crues subites de 2018 au Luxembourg. LIST, Luxembourg, 2020.

Pistocchi, Alberto: Leaf Area Index (MAPPE model), European Commission, Joint Research Centre (JRC) [Dataset] PID: http://data.europa.eu/89h/jrc-mappe-europe-setup-d-18-lai, 2015.

Ruiz-Villanueva, V., Borga, M., Zoccatelli, D., Marchi, L., Gaume, E., and Ehret, U.: Extreme flood response to shortduration convective rainfall in South-West Germany, Hydrology and Earth System Sciences, 16(5), 1543-1559, https://doi.org/10.5194/hess-16-1543-2012, 2012.

Saber, M., and Yilmaz, K. K.: Evaluation and Bias Correction of Satellite-Based Rainfall Estimates for Modelling Flash

Floods over the Mediterranean region: Application to Karpuz River Basin, Turkey, Water, 10(5), https://doi.org/10.3390/w10050657, 2018.

Sato, Y., Kumagai, T., Kume, A., Otsuki, K., and Ogawa, S.: Experimental analysis of moisture dynamics of litter layersthe effects of rainfall conditions and leaf shapes, Hydrological Processes, 18(16), 3007-3018, https://doi.org/10.1002/hyp.5746, 2004.

710 Scaini, A., Hissler, C., Fenicia, F., Juilleret, J., Iffly, J. F., Pfister, L., and Beven, K.: Hillslope response to sprinkling and natural rainfall using velocity and celerity estimates in a slate-bedrock catchment, Journal of Hydrology, 558, 366-379, https://doi.org/10.1016/j.jhydrol.2017.12.011, 2018.

Sidle, R. C., Tsuboyama, Y., Noguchi, S., Hosoda, I., Fujieda, M., and Shimizu, T.: Stormflow generation in steep forested headwaters: a linked hydrogeomorphic paradigm, Hydrological Processes, 14(3), 369-385,

715 https://doi.org/10.1002/(SICI)1099-1085(20000228)14:3<369::AID-HYP943>3.0.CO;2-P, 2000.

Sidle, R. C., Hirano, T., Gomi, T., and Terajima, T.: Hortonian overland flow from Japanese forest plantations-an aberration, the real thing, or something in between?, Hydrological Processes, 21(23), 3237-3247, https://doi.org/10.1002/hyp.6876, 2007.

Slim, M., Perron, J. T., Martel, S. J., and Singha, K.: Topographic stress and rock fracture: a two-dimensional numerical

720 model for arbitrary topography and preliminary comparison with borehole observations, Earth Surface Processes and Landforms, 40(4), 512-529, https://doi.org/https://doi.org/10.1002/esp.3646, 2015. 
Teschemacher, S., Rieger, W., and Disse, M.: Experimental Investigation of Lateral Subsurface Flow Depending on Land Use and Soil Cultivation, Water, 11(4), 766, https://doi.org/10.3390/w11040766, 2019.

Tramblay, Y., Bouvier, C., Martin, C., Didon-Lescot, J.-F., Todorovik, D., and Domergue, J.-M.: Assessment of initial soil moisture conditions for event-based rainfall-runoff modelling, Journal of Hydrology, 387(3-4), 176-187, http://dx.doi.org/10.1016/j.jhydrol.2010.04.006, 2010.

Van Campenhout, J., Hallot, E., Houbrechts, G., Peeters, A., Levecq, Y., Gérard, P., and Petit, F.: Flash floods and muddy floods in Wallonia: recent temporal trends, spatial distribution and reconstruction of the hydrosedimentological fluxes using flood marks and sediment deposits, Belgeo, Revue Belge de Géographie, (1), https://doi.org/10.4000/belgeo.16409, 2015.

730 Vannier, O., Braud, I., and Anquetin, S. Regional estimation of catchment-scale soil properties by means of streamflow recession analysis for use in distributed hydrological models, Hydrological Processes, doi:10.1002/hyp.10101, 2013.

Westhoff, M. C., Bogaard, T. A., and Savenije, H. H. G.: Quantifying spatial and temporal discharge dynamics of an event in a first order stream, using distributed temperature sensing, Hydrology and Earth System Sciences, 15(6), 1945-1957, https:// doi.org/10.5194/hess-15-1945-2011, 2011.

735 Wrede, S., Fenicia, F., Martínez-Carreras, N., Juilleret, J., Hissler, C., Krein, A., Savenije, H. H. G., Uhlenbrook, S., Kavetski, D., and Pfister, L.: Towards more systematic perceptual model development: a case study using 3 Luxembourgish catchments, Hydrological Processes, 29(12), 2731-2750, https://doi.org/10.1002/hyp.10393, 2015.

Zavala, L. M., González, F. A., and Jordán, A.: Intensity and persistence of water repellency in relation to vegetation types and soil parameters in Mediterranean SW Spain, Geoderma, 152(3), 361-374, doi.org/10.1016/j.geoderma.2009.07.011, 7402009. 